\title{
Atimoi por deudas. Expulsión y reintegración de atimoi en Atenas clásica
}

Recibido: 05/03/2021. Aceptado: 27/08/2021.

\section{Resumen}

En estas páginas vamos a tratar un tipo particular de atimia, la atimia por deudas en Atenas clásica, así como el tema de la rehabilitación de atimoi (en un sentido más amplio) en momentos decisivos o claves de la historia de Atenas vinculados a situaciones de crisis aguda en los que se percibe una voluntad/necesidad de ampliar el cuerpo cívico. La rehabilitación de atimoi en masa (en ocasiones junto a otros colectivos) tuvo que ser demográfica y militarmente significativa en época clásica.

Palabras clave: deudores públicos, decreto de Patroclides, rehabilitación de colectivos excluidos en la ciudadanía, demografía.

\section{Atimoi for Debts. Expulsion and Reintegration of Atimoi in Classical Athens}

\begin{abstract}
In these pages I deal with a particular type of atimia, the atimia for debts in classical Athens, as well as the issue of the rehabilitation of atimoi (in a broader sense) at decisive or key moments in the history of Athens linked to acute crisis situations in which a desire / need to expand the civic body is perceived. The mass rehabilitation of atimoi (sometimes together with other groups) had to be demographically and militarily significant in classical times.
\end{abstract}

Keywords: public debtors, Patroclides' decree, rehabilitation of excluded groups in citizenship, demography. 


\section{Introducción ${ }^{1}$}

El tema de los atimoi ha suscitado un debate extenso que toca distintos aspectos como el cambio de significado del término entre arcaísmo y clasicismo y la crítica a esta idea, o también las circunstancias de rehabilitación de los atimoi en Atenas arcaica y clásica. En este estudio nos centraremos especialmente en dos aspectos: por una parte, en los atimoi por deudas de época clásica (particularmente en lo que podría atañer a los pequeños-medianos deudores) y por otra, en las rehabilitaciones de atimoi en ese periodo. Pretendemos con ello mostrar, por un lado, la amplitud de situaciones y de personas que pudieron estar afectadas por la atimia, especialmente por deuda pública en Atenas clásica, y, por otro, las necesidades sociales, demográficas y militares de Atenas como causa de amnistía en distintos momentos clave que examinaremos: Maratón (490 a. C.), en el 405 a. C. con el decreto de Patroclides tras Egospótamos, y justo después de Queronea (338 a. C.) a propuesta de Hiperides. No vamos a tratar las amnistías del 404 y la posterior a la restauración de la democracia en el 403 por responder fundamentalmente-sin que puedan dejarse de considerar tampoco otras causas como las que aquí proponemos- a motivaciones de carácter político, en unas circunstancias específicas complejas que merecen un estudio aparte. Tampoco nos adentraremos en la amnistía de Solón que concierne fundamentalmente a deudores de todo tipo, tanto públicos como privados, que trataremos en otro lugar.

\section{El polémico decreto de Patroclides y el resumen de Andócides}

Quizás el caso más conocido de deudores en Atenas clásica es el de los deudores públicos. En el resumen de Andócides, cuando alude al decreto de Patroclides del $405,{ }^{4}$ se colocan en primer lugar y se habla (sin que necesariamente tenga que ser una lista exhaustiva) $)^{5}$ de los magistrados que debían dinero después de sus euthynai, ${ }^{6}$ deudores como resultado de una demanda de expulsión (dike exoules),

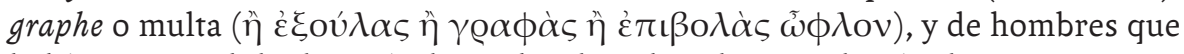
habían incumplido después de recibir derechos de recaudación de impuestos, "o bien extendieron garantías a nombre del tesoro". Todos estos deudores públicos

\footnotetext{
1 Este artículo se ha realizado con la ayuda del Proyecto UCM-Santander: PR87/19-22580: Construcción cultural e “integración” de los excluidos en la Atenas democrática (ss. VI-IV a. C.) y con el Proyecto del Ministerio PID202011279oGB-loo: Pobreza, marginación y ciudadanía en Atenas clásica. Procedimientos de marginalización e integración ciudadana de sectores liminales en el sistema democrático.

2 Se discute si “atimos" cambió de sentido entre arcaísmo y clasicismo, tesis emitida fundamentalmente por Swoboda (1893) y seguida por varios autores como Hansen (1976) aunque con distintas posturas en la fecha de este cambio. Con dos sentidos tanto en época arcaica como clásica: Dmitriev (2015). Realza los dos significados, moral y legal: Maffi (1983). Crítica al supuesto cambio de sentido: Youni (2001, 2018, 2019); Joyce (2018). Ver, sin embargo: Maffi (2018).

3 Para la restauración de la democracia en el 403 y la amnistía véase: Arist. [Ath. Pol.] 39; Hansen (1976, 68-69); Loraux (2008 [2005]); Shear (2011); Gallego (2012); Teegarden (2014). Para la reintegración de los exiliados después de la rendición frente a Esparta tras la derrota de Egospótamos en el 404: And. 1.80; Arist. [Ath. Pol.] 34.3 (ambos: atimoi y exiliados); Rhodes (1981, 430-431); Rubinstein (2018, pp. 5-6, con más bibliografía); según este autor, estos retornados no lo tendrían fácil para recobrar sus propiedades tras la restauración democrática en el 403 (2018, p. 16).

4 And. 1.73 ss. Para el texto de Andócides: MacDowell (1962, pp. 106-113); Harrison (1971, pp. 173-176); Hansen (1976, pp. 55-90); Boegehold (1990); Poddighe (2006); Pébarthe (2006, pp. 232-234); Kamen (2013, pp. 75-81). Contra la autenticidad del decreto en sí ver infra notas 10 y 12.

5 Hansen (1976, p. 85).

6 Ver infra en el texto.

7 Traducción de Redondo Sánchez (1991). El impago de la eisphora, sin embargo, no era motivo de atimía: Harrison (1971, p. 172); Hansen (1976, p. 6o). Tampoco la deuda de los trierarcos: Hunter (2000, 31-32).
} 
habían caído, a través de un juicio o automáticamente, en atimía. Los deudores públicos eran inscritos en la acrópolis en una lista común en una tabla de madera (sanis), ${ }^{10}$ pero, además, es posible que hubiera listas de deudores en documentos públicos de distinto tipo o procedencia, según fuese el magistrado que los recogía inicialmente (praktores y basileis, entre otros) como ha postulado Hansen. ${ }^{11}$ El decreto de Patroclides del 405, aprobado por la asamblea justo inmediatamente después de la pérdida en Egospótamos cuando Atenas se preparaba para un asedio -como también mencionan Jenofonte y Lisias-, ${ }^{12}$ ha generado recientemente controversia sobre su veracidad. Especialmente se ha discutido en un artículo de Canevaro y Harris, rebatido por Hansen, a quien contestan posteriormente estos autores con nuevos argumentos. ${ }^{13}$ Uno de los problemas, entre otros, es que no coinciden exactamente los que forman parte del resumen de Andócides (1.73-76) con los del decreto propiamente dicho (1.77-78), en el que no aparecen todas las categorías (ni del mismo modo) que las enunciadas por Andócides. Ya en los años 90 Boegehold sugirió que el interés, en este caso (en el decreto), es en insistir en la destrucción de las listas en documentos públicos en los que aparecían atimoi, idea en la que incide Hansen posteriormente, quien señalaba que el decreto simplemente decía "que vote el pueblo aquello mismo que cuando ocurrieron las guerras médicas" (1.77) y que sería, por tanto, similar a lo que señala Andócides en su resumen, algo que Harris y Canevaro consideran demasiado vago, resaltando la inverosimilitud de la ausencia de alguna fórmula como la introducida por el

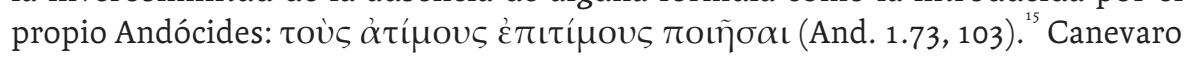
y Harris sostienen que esta y otras desavenencias, así como las inconsistencias del lenguaje y de las fórmulas del decreto con respecto a los decretos del siglo V, indican claramente que se trata de una falsificación de época helenística. ${ }^{1 .}$ Para Hansen, sin embargo, alguna de estas inconsistencias como la ausencia de las excepciones en el resumen de Andócides, que sí aparecen en el decreto (1.78), indicarían que Andócides está poniendo el acento en los que se rehabilitan y

8 Dem. 58.49 dice que un deudor público es atimos desde el momento en que debe dinero al Estado (es decir antes de un juicio). Esto llevó a varios autores a señalar una atimía automática y otra derivada de un juicio: MacDowell (1962, p. 138); Harrison (1971, pp. 171-72); Hansen (1976, pp. 55-98); Wallace (1998) habla de "unconvicted or potential atimos". Ver Kamen (2013, p. 75 con n. 5), con más bibliografía.

9 Ver el resumen de Andócides en 1.73-76 y el polémico decreto de Patroclides en Andócides 1.77-78. Para bibliografía sobre el decreto ver nota 3 y 10 y 12.

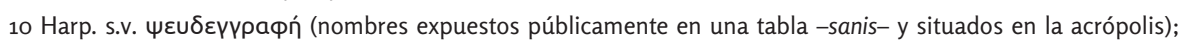
Agora XIX: P26, lin. 494-5, 505, 508-9; Dem. 58.19; Dem. 25.28 (lista de deudores públicos guardados por tesoreros de Atenea en la acrópolis). Para sanides: Sickinger (1999, pp. 110-111) que menciona el uso de tablas de madera-sanides, pinakia y grammateia- en el siglo V por parte de magistrados atenienses (1999, p. 208). Para registro de documentos públicos: Faraguna (2017, esp. p. 33: tablas de deudores en la acrópolis).

$11 \mathrm{El}$ texto (And. 1.77) habla de los praktores, los tamías de la diosa y de otros dioses y los basileis: عí̧ toùç прá-

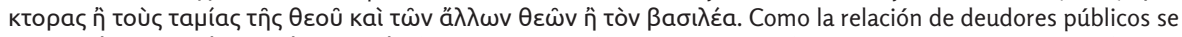
conservaba en una lista en la acrópolis (ver nota anterior), Canevaro-Harris (2012, p. 104; 2016, pp. 17, 18-21) argumentaron que era un signo de inautenticidad de la ley. Sin embargo los argumentos de Hansen (2015, pp. 889-890; también en Carawan, 2013, p. 48), aunque no concluyentes, dejan abierta la puerta a la posibilidad de diversidad de listas de deudores o de copias de documentos con registro de deudores en Atenas en los archivos de varios magistrados - además de la lista de la acrópolis - lo que hace comprensible también la afirmación de Andócides (1.76) de: "Pues bien, votasteis a favor de borrar todos esos decretos, tanto estos en si como cualquier copia, donde-

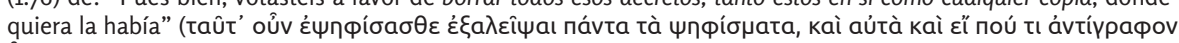
ก̉v) (Traducción de Redondo Sánchez, 1991), también recordado en And. 1.103. Para praktores que cobran multas (y saben, por tanto, quienes deben registrarse como deudores públicos): Harrison (1971, p. 187); Antiph. 6.49; IG I359 (430 a.C.), fr. e, lin. 47-8; IG II2 45 (378/7 a.C.), lin. 7.

12 También mencionado: Jenofonte (Xen. Hell. 2.2.11) y Lisias (Lys. 25.27).

13 Decreto como falsificación: Canevaro-Harris (2012; 2016-2017, esp. p. 10, n. 3); Novotný (2014: p. 74 y ss.). Trataron, sin embargo, de defender la autenticidad del mismo: Carawan (2013, pp. 47-49), y, sobre todo, Hansen (2015).

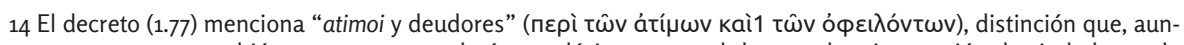
que se encuentra también en otros textos de época clásica -como el decreto de reintegración de ciudadanos de Hiperides (Hyp. Fr. 29 Jensen -Poddighe, 2006, p. 10-; Dem. 58.45; Arist. [Ath. Pol.] 63.3; Dem. 24.45-46)-, no está exenta de problemas: Canevaro-Harris (2016-2017, pp. 23-24).

15 Canevaro-Harris (2016-2017, pp. 12-13). También señalado por Jenofonte y Lisias (ver nota 11).

16 Canevaro-Harris (2012; 2016-2017). 
no en los que no lo hacen. El decreto especifica que en el caso de los que no se rehabilitan los documentos físicos no debían ser destruidos. ${ }^{17}$

En estas páginas nos centraremos en los deudores del resumen de Andócides que en términos generales parece ser aceptado como válido para el estudio de los atimoi, pero antes señalaremos qué otras categorías de atimoi menciona este autor en su síntesis. Después de los deudores, Andócides se refiere a aquellos que tenían atimía total pero que no perdían sus propiedades (1.74): personas condenadas por robo o por aceptar sobornos; además, todos los que desertaron en el campo de batalla, los que fueron declarados culpables de evasión del servicio militar, de cobardía o de desertar de un combate naval, ${ }^{19}$ aquellos que arrojaron sus escudos y los que fueron condenados tres veces como reos de falso testimonio o de falsa citación ${ }^{20}$ y los que fueron declarados culpables de maltrato a sus padres. A continuación (1.75) habla de los que habían perdido sus derechos por decreto (este sería el caso de Andócides) ${ }^{21}$ y que el orador parece que deliberadamente confunde con aquellos que han perdido sus derechos solo de forma parcial (1.75-76); estos son soldados (oí $\sigma \tau \varrho \alpha \tau \iota \tilde{\omega} \tau \alpha \mathrm{l}$ ) del golpe oligárquico del 411 que habían permanecido en Atenas y a los que se había sancionado con la prohibición de participar en la asamblea y en el Consejo. En cualquier caso, parece que el decreto no estipulaba el retorno de los oligarcas que estaban en el exilio fuera de Atenas. ${ }^{22}$ La atimía parcial afectaba a aquellos a los que "no les estaba permitido formular denuncias, a otros el presentar demandas de endeixis; la prescripción para algunos fue la de que no se hicieran a la mar hacia el Helesponto; para otros, que no lo hicieran rumbo a Jonia; para unos terceros, que no entraran en el ágora". ${ }^{23}$ El resumen de Andócides no es exhaustivo y pudo haber, sin duda, otros casos.

\section{Deudores atimoi en época clásica}

Todos los deudores públicos, cuya condición de atimoi se heredaba (hasta que la deuda fuera satisfecha), estaban bajo la jurisdicción de la Boule, que supervisaba las finanzas públicas en Atenas. ${ }^{25}$ Los deudores del Estado estaban obligados a pagar en el plazo de ocho pritanías. Pasado ese tiempo, en la novena pritanía, la suma adeudada se duplicaba, se convertían en atimoi y sus bienes eran confiscados al menos -igual que la condición de atimos- hasta que la deuda fuera pagada. ${ }^{26}$ En general los casos

17 Hansen (1976, p. 89); Boegehold (1990, p. 150 y ss.); Hansen (2015, pp. 887-888).

18 Canevaro-Harris (2012, p. 125).

19 Para este tipo de graphai: Harrison (1971, pp. 32, 82). Para deserción del servicio militar en la infantería: Lys. 14.5-7; Hamel (1998); Van Wees (2018, pp. 5-6, 8-9).

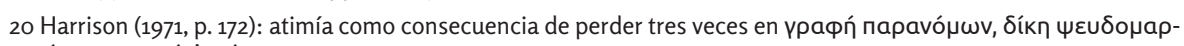
tupíwv у үрафń ápүíac.


22 And. 1.80. Carawan (2002, p. 15): “Patrocleides' decree had not recalled those exiled for past offences; it simply offered security to those who remained". In 403, however, there was a general recall of exiles (with the usual exceptions) and Andocides therefore saw fit to return". En la misma línea: Hansen (2015, pp. 896-897), que distingue entre "the amnesty for atimoi and opheilontes issued in 405 by the decree proposed by Patrokleides, and the amnesty for pheugontes issued in 404 after the Athenians had surrendered". Cree que la amnistía del 490 fue idéntica a la del 405 (solo los atimoi), pues, aunque Andócides (1.107-108) habla de la integración de los que estaban en el exilio (pheugontes), confunde en el texto Maratón con Salamina (la destrucción de Atenas). Se trataría, por tanto, como señala Hansen (2015, p. 897) de dos amnistías separadas tanto a inicios del siglo V como a finales del mismo (pp. 405, 404).

23 Traducción de Redondo Sánchez (1991).

24 Hansen (1976, pp. 71-72); Hunter (2000, pp. 29). Dmitriev (2015, pp. 45-48).

25 Rhodes (1972, pp. 88-113, 148-152).

26 Procedimiento de confiscación se llama apographe: Harrison (1971, pp. 211-217); MacDowell (1978, p. 166); Osborne (1985, pp. 44-48), quien indica los distintos tipos de apographe. La apographe es una graphe en la que cualquiera (ho boulomenos) puede proponer que la propiedad de alguien que debe dinero al Estado sea confiscada y utilizada para pagar la deuda. El que inicia la demanda presenta una lista (apographe) de propiedades (tierras, casas, esclavos, etc.) 
que se conocen de deudores públicos conciernen a gentes con grandes patrimonio o ricos, capaces de arrendar las tierras públicas, contratistas que recolectaban tasas, garantes de una deuda al Estado, o los que habían comprado del Estado derechos de explotación de minas, por ejemplo. ${ }^{27}$ En cualquier caso, si eran condenados y no podían pagar, perdían su propiedad que era confiscada y permanecían ellos y sus hijos en ese estatuto hasta que pudieran pagar la deuda (si es que podían); es decir, engrosaban las filas de "desclasados" o excluidos/marginalizados dentro del a ciudad. Cabe suponer, quizás, que los más ricos podían tener recursos en otros lugares y, en ocasiones, podrían volver a amasar de nuevo fortuna fuera de Atenas, retornando después a la ciudad.

Sin embargo, nos interesan especialmente aquí los deudores públicos de condición más modesta, principalmente muchos de entre los que Andócides menciona como:

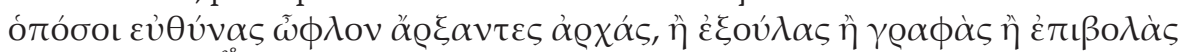
$\tilde{\omega} \phi \lambda$ ov $(1.73){ }^{28}$ En primer lugar, nos fijaremos en los que habían ejercido como

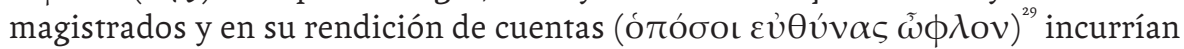
en atimía por deber al Estado y no pagar, ${ }^{30}$ o bien como pena pecuniaria (no satisfecha) por incumplir con las obligaciones de su cargo. No hay que olvidar que con Efialtes (Arist. [Ath.Pol.] 26.2) el arcontado se abre a los zeugitai y desde antes estos ya podrían desempeñar magistraturas menores. ${ }^{31}$ Estaban sujetos a rendición de cuentas los magistrados (incluidos los miembros de la boule), embajadores y sacerdotes que hubieran manejado fondos o propiedad pública, pero, además, todos los oficiales podían ser inculpados por incumplimiento de sus obligaciones -como muestra claramente la epigrafía- y condenados normalmente a una pena pecuniaria. ${ }^{32}$ El procedimiento de rendición de cuentas ${ }^{33}$ en el siglo IV está recogido por la Constitución de Atenas. En cada pritanía un comité de la boule, llamados logistai (Arist. [Ath. Pol.] 48.3), examinaba las cuentas de cada magistrado, siendo posible que si el comité no quedaba satisfecho se pudieran iniciar procesos en los tribunales contra el magistrado; además, estos tenían que pasar una rendición de cuentas al finalizar el cargo llevada a cabo por 10 logistai, asistidos por synegoroi, elegidos por sorteo (Arist. [Ath. Pol.] 54.2) que debían llevar

que propone que sea confiscada. Los magistrados encargados de estos casos son los Once y las listas eran leídas en la principal reunión (kyria) de la asamblea del mes siguiente, para avisar a cualquiera que considerara que alguna parte de esas propiedades le pertenecía. Cuando había varios que reclamaban en el juicio, este se llamaba diadikasia (en este caso cada uno de los participantes tenía que poner en depósito un quinto del valor de lo reclamado que revertía en el Estado si perdía la causa). Si el tribunal determinaba que la propiedad tenía que ser confiscada por el Estado, se pasaba a los poletai (los oficiales que venden propiedades estatales) que lo vendían en una subasta. Lo que se sacaba se utilizaba para saldar deuda. Si era suficiente, el deudor dejaba de ser atimos y se le devolvía lo que sobraba, pero si no, se reducía la cantidad, aunque seguía siendo atimos y deudor. El Estado daba al que iniciaba el proceso una parte de la cantidad que recobraba el Estado aunque no siempre era así (Osborne, 1985, pp. 45-47).

27 Arrendamiento o tenencia de propiedades del Estado: Dem. 47.22; Derechos de minas: Dem. 37.22; Arist. [Ath. Pol.] 47.2-48.1. Ver Harrison (1971, p. 172). Hansen (1976, p. 55 y ss.); Hunter (2000), con más fuentes y casuística. Esta autora clasifica a los deudores públicos en tres amplias categorías: 1) los que poseen o se han apropiado de propiedad pública de manera indebida; 2) aquellos que había contratado el Estado como recaudadores de impuestos y arrendatarios de propiedad pública o minería; 3) a quienes se les impuso una multa.

28 “cuantos tras haber desempeñado magistraturas fueron reconocidos deudores de concusión, o de prácticas de evicción, o de acusaciones, o de multas" (Traducción de Redondo Sánchez, 1991). Estarían todos ellos dentro de la tercera categoría en la clasificación de Hunter: ver nota anterior.

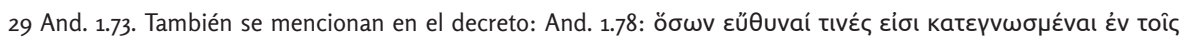

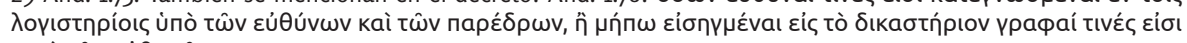



30 Ver, por ejemplo, el caso de Teocrines, como comisario de su tribu, deudor de 700 dracmas debidas al héroe epónimo de su tribu en sus euthynai cuando dejó el cargo: Dem. 58.14.

31 Sin que podamos descartar que en el Consejo pudieran entrar thetes, sobre todo, quizás, desde fines del siglo $\mathrm{V}$ por los problemas demográficos, haciendo la vista gorda al requisito censitario para ser magistrado. Ver Hansen (1991, p. 249).

32 Scafuro (2014). Para el número de magistrados (70o anualmente, según Aristóteles: [Ath. Pol.] 24.3): Hansen (1980).

33 Para euthynai de magistrados ver Harrison (1971, pp. 14-15, 28-31, 208-211). Piérart (1971); Scafuro (2014, pp. 301-303).

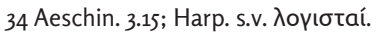


el caso a un dikasterion de 501 miembros; ellos mismos (a través de los synegoroi, sus asistentes) o cualquier ciudadano (ho boulomenos) podían presentar un cargo en los tribunales por malversación ( $\gamma \varrho \alpha \phi \eta ́ ~ \kappa \lambda о \pi \tilde{\eta} \varsigma$ ), recepción de sobornos ( $\delta \tilde{\omega} \varrho \alpha \lambda \alpha \beta o ́ v \tau \alpha)$ o, más en general, uso indebido de fondos o propiedad públicos

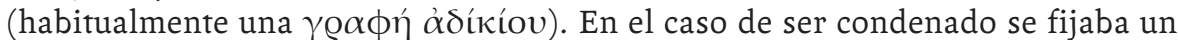
importe a pagar. En el caso de malversación o soborno, la pena estaba fijada por ley en diez veces la cantidad malversada o recibida como soborno. Si la pena era

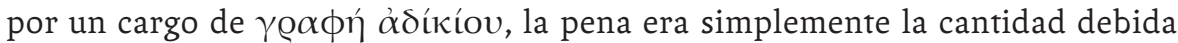
determinada por estimación. Si esta multa no se pagaba en la novena pritanía, se doblaba (no así las otras dos). Es posible que si había actuado un ciudadano privado en el proceso recibiera al menos una parte de la multa. La rendición de cuentas, en materias no financieras, las llevaban los diez euthynoi quienes podían imponer penas pecuniarias por incumplimiento de las obligaciones de los magistrados; estaban asistidos por los paredroi, y al término del año se sentaban junto a los héroes epónimos para recibir cualquier cargo, público o privado, contra un magistrado en el ejercicio de su mandato. Si el euthynos consideraba que el acusado era culpable transmitiría el caso a los tribunales (Arist. [Ath. Pol.] 48.4-5). ${ }^{35}$ No se sabe si el procedimiento era el mismo en el siglo $\mathrm{V}$ aunque probablemente en esos momentos los magistrados eran también sometidos a una auditoría financiera y a otra relativa a su conducta en relación con las funciones y obligaciones de su cargo. ${ }^{36}$ Probablemente ambas rendiciones de cuentas eran llevadas ante los euthynoi en ausencia, en esos momentos, de los logistai. ${ }^{37}$ En un estudio reciente Scafuro examina la evidencia epigráfica en la que se ponen de manifiesto las penas pecuniarias o multas de distinta índole impuestas a los magistrados que incumplían sus funciones al término del mandato. Probablemente los euthynoi realizaban un juicio preliminar y decidían si eran culpables, imponiendo una sanción monetaria y pasando el caso a los jueces por demos, si era un caso privado, o a los thesmothetai para ser juzgado en un tribunal, en un caso público. ${ }^{38}$ Si los magistrados eran condenados y no pagaban la pena impuesta pasaban a engrosar las filas de los atimoi deudores. En las inscripciones se utiliza el verbo $\varepsilon \dot{v} \theta u ́ v \varepsilon \sigma \theta \alpha \iota$ para indicar que si los magistrados (y en algunos casos otras personas "privadas") no

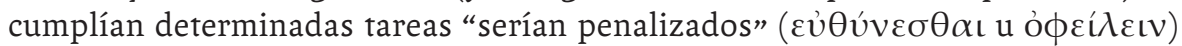
con una pena monetaria; estas varían en el registro epigráfico, desde 2 dracmas a 10.000, pasando por $100 \mathrm{y}$, con frecuencia, de $1.0000^{39}$ Las sanciones más elevadas tienen, en los decretos, como señala Scafuro, un efecto disuasorio, pero esto no es óbice para que no se impusieran en ocasiones en casos de incumplimiento. ${ }^{40}$ Para los medianos (y no tan medianos) propietarios, sanciones monetarias de esta

\footnotetext{
35 Ver bibliografía en nota 32.

36 Así parece atestiguarlo una inscripción del 417: IG I3 52A.24-29; Scafuro (2014, pp. 301-302). Para ejemplos de euthynai en las fuentes en el s.V: Scafuro (2014, pp. 302-303), quien comenta también el pasaje de Andócides 1.78 (2914, pp. 303-304) del supuesto decreto de Patroclides sobre este punto que alude al "logisterion" como sede de los euthynoi y paredroi en el siglo V, algo que parece que confirma Lisias (Lys. 20.10).

37 Esta es la tesis de Piérart (1971, pp. 526-573). Los logistas del siglo V (IG I3 52, lin. 7-9 y 369, lin. 1) no son los mismos que los del siglo IV, sino un cuerpo de treinta que sirven como contables del tesoro (Scafuro, 2014, pp. 304-305).

38 Es decir, no tomaban la decisión final. Se inclina por esto Scafuro (2014, pp. 318-321). Ver la discusión sobre si imponían las penas directamente o el caso pasaba a un tribunal: Hansen (2015, p. 893) y Canevaro-Harris (2016-2017, pp. 24-27). Referencia a euthynoi y paredroi: IG Il2 1629, lin. 238-242 (decreto del 325 a.C.); Scafuro (2014, pp. 306-307).

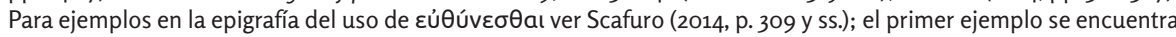
en el decreto de Salamina del 510: IG I3 1, lin. 7-8. Para los textos epigráficos en los que aparece, en cambio, el término

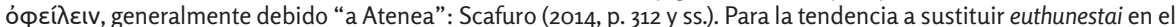
siglo IV en general (aunque con excepciones) por opheilein: Scafuro (2014, pp. 307-308). Uso de euthunesthai también en textos de fratrías y/o gene: SEG XXIII 22 (460-440 a.C.: de fratría o genos); IG I3 243D, lin. 103, 130-1 (ley sacra de Melita de 480-450); Scafuro (2014, p. 315). El primer texto que muestra la existencia de euthynoi es el decreto de un demo, el de Skambionidai, del 460 a.C.: IG 13 244; Scafuro (2014, p. 305).

39 Referencias en Scafuro (2014, 317-318) tanto con término euthunesthai como opheilein.

40 Euthunesthai "is not simply "to be penalized" but "to be condemned at one's end of term euthynai": Scafuro (2014, p. 325). Acusadores voluntarios irían al monumento de los héroes epónimos a llevar información y cargos contra magistrados o particulares que no hubieran cumplido determinadas tareas o funciones oficiales estipuladas por decreto. El euthynos llevaba el caso al tribunal y establecía la sanción legal.
} 
envergadura (o incluso menores, como 100 dracmas) podría ponerles en la tesitura de terminar siendo atimoi por deudas impagadas al Estado, tanto a magistrados como a particulares que incumplieran las normativas de un decreto. ${ }^{4}$

En segundo lugar, nos interesan también aquellos atimoi por impago de multas al

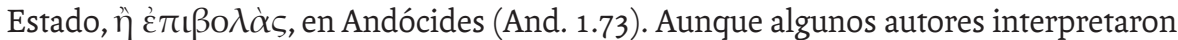
las epibolai del texto como multas impuestas únicamente por los magistrados, ${ }^{42}$ otros parecen inclinarse por un abanico más amplio, incluyendo las multas establecidas por la boule de $500,{ }^{43}$ y aquellas derivadas de un juicio ${ }^{44}$-en las Avispas de Aristófanes aparece el término epibole como multa impuesta por un tribunal $-^{45}$, como las ya señaladas en el caso de la rendición de cuentas. Además de las multas, podrían incluirse en este apartado también los impagos al erario público de las costas de un juicio (prytaneia) de las que no habla directamente Andócides. Estos pagos se hacían para prevenir el abuso del sistema judicial. Estaba estipulado que se aportaran unas tasas (prytaneia) por parte de ambos contendientes en los juicios privados (dikai) si el litigio superaba las 100 dracmas; el que perdía debía pagar, además, al ganador del juicio la tasa que habría aportado con antelación. ${ }^{46}$

Dentro de las multas derivadas de juicios, un tipo especial eran las $\dot{\varepsilon} \pi \omega \beta \varepsilon \lambda i ́ \alpha$, equivalentes a un sexto del valor de lo reclamado en el juicio ( 1 óbolo por cada dracma) pagado al oponente por parte del perdedor del litigio. ${ }^{47}$ No es impensable, como postuló Hansen, que, en algunos casos, como parece indicar el testimonio de Demóstenes (27.67) y de Isócrates (18.35), se tuviera que pagar una cantidad igual al Estado y, en esa tesitura, si las deudas no eran satisfechas, conllevarían la atimía. ${ }^{48}$

41 En leyes sacras suele ser frecuente el uso de este tipo de fórmula para particulares que incumplieran las normas prescritas como en el caso, por ejemplo, de la ley que regula la conducta en el recinto de las Ninfas; el que la transgreda debe una multa (opheilein) de 50 dracmas a las Ninfas: IG I3 256 (440-430 a. C.); otros ejemplos en: Scafuro (2014, p. 316). En cualquier caso, también se daban en leyes no sacras, como las de los demos (ej: IG I3 245 del 470460 a. C.); en este caso el dinero se debe pagar a las arcas del demo.

42 Harrison (1971, p. 173) relaciona el término en el texto de Andócides únicamente con las multas impuestas por los

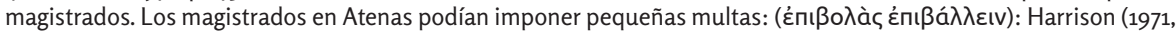
pp. 4-6); Hansen (1980, p. 153); Allen (2000, pp. 41-42). Aeschin. 3.27. Hieropoioi de las Panateneas con capacidad para imponer pequeñas multas: IG II2 334.34. Lexiarchoi imponen multas a los que se evaden de la asamblea: Poll. 8.104, etc (más fuentes en Harrison, 1971, 4, n. 1). Hieropoioi en Hephaisteia pueden imponer 50 dracmas de multa. IG I3 82, lin. 25-28 (421 a.C.); el basileus, acompañado del praktor y del grammateus, puede imponer multas en la celebración de los Misterios (SEG XXX 61, lin. 27-38). Cf. Scafuro (2014, p. 319). La multa se imponía en el acto. Generalmente los magistrados tienen de tope entre 10 y 50 dracmas, pero la Boule podía multar con 500 dracmas: ver nota siguiente. 43 La boule podía imponer multas hasta 500 dracmas: Harrison (1971, pp. 55-56); Allen (2000, p. 41).

44 Generalmente interpretado como multas impuestas por un magistrado, pero MacDowell (1962, ad. loc.) las interpreta también como multas impuestas por un jurado. Un tribunal podía confirmar la multa impuesta por un magistrado: Harrison (1971, p. 5). Lys. 6.11. También las impuestas por los eythunoi: ver supra en el texto. Para multas véase también Rubinstein (2000, p. 94, n. 40): multa standard de 1.000 dracmas. Para cantidades de multas impuestas por euthynoi que luego serían ratificadas por un tribunal: Scafuro (2014, pp. 317-318).

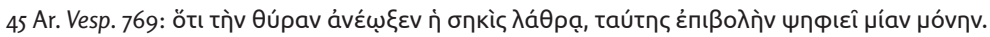

$46 \mathrm{Si}$ el juicio era por un importe por debajo de 100 dracmas no se pagaban tasas; si el litigio era por un importe entre 100 y 1.000 dracmas, se pagaban 3 dracmas; por un importe de más de 1.000 dracmas se pagaban 30 dracmas por cada litigante. Para prytaneia en acciones judiciales por deuda ver: Ar. Nu. 1136, 1180, 1197, 1199, 1255; Poll. 8.38; Harrison (1971, pp. 92-93). En los juicios públicos en general no había prytaneia, salvo en los casos de procesos por phasis (Harrison, 1971, pp. 94, 220-221). Pago de prytaneia: Dem. 47.64. Ver Thür (2015, pp. 36-38).

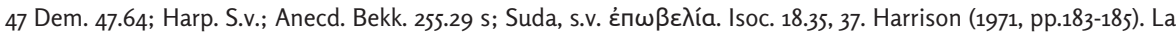
epobelía es una multa, por tanto, en la que incurre alguien que pierde un juicio en ciertos tipos de dike, como, por ejemplo, dike epitropes (Dem, 27.67, 69; Dem. 28.18,31; Dem. 31.14), dike chreos (Dem. 35.46; Dem 56.4) o en la incierta dike parabaseos sunthekon (Aischin. 1.163); también en un juicio que obtiene menos de un quinto de votos en dike pseudomartyrion presentado en conexión con una diamarturía (para esta: Harrison, 1971, pp. 124-131). Por un litigante que pierde paragraphe (Isoc. 18.35; Harrison, 1971, 106-124) o una antigraphe (Harrison, 1971, pp. 131-133) y quizás a pagar también por el demandante en un juicio de phasis (Poll. 8.48; no seguro: Harrison, 1971, p. 184). Algunos gramáticos señalaron que la multa debía pagarse por cualquier demandante que no tuviera éxito en un litigio monetario (Anecd. Bekk, 255.29s), aunque no es así en Isócrates (18.12) que señala que sólo arriesgaba los prytaneia. Ver para el tema también: Thür (2015, p. 39).

48 Hansen (1982, pp. 115-116). 
En definitiva, la casuística de multas podía ser amplia y afectaría probablemente, en estos casos, a un extenso abanico social, no solo a los inicialmente con potencial económico, sino también a medianos/pequeños propietarios. A ambos costes (tasas y multas) puede referirse Blépiro en la Asambleístas en el pasaje en el que muestra su preocupación cuando pregunta a Praxágoras (Eccl. 655): ¿Qué pasará si uno pierde

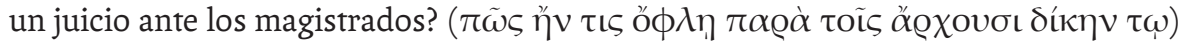

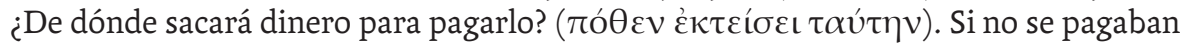
las costas - prytaneia- (las propias y las del contendiente vencedor) y/o las multas (si eran debidas al Estado, como en el caso de la rendición de cuentas y en otros, como la dike exoules, entre otras), se convertían en deudores públicos y, por tanto, sus propiedades eran confiscadas. Si las propiedades no eran suficientes para pagar la deuda, seguían siendo atimoi.

Un caso especial, resaltado por Andócides en su resumen, junto con la rendición de cuentas, las multas y las graphai, es el de la dike exoules ( $\dot{\xi} \xi o u ́ \lambda \alpha \varsigma$ : And.1.73) que comportaba deuda pública. Aquellos que se habían endeudado frente a uno o varios ciudadanos particulares y que se habían negado a pagar, podían ser objeto de una dike exoules. Si bien no satisfacer una deuda privada ${ }^{50}$ no comportaba la atimía en época clásica, aunque algunos casos son dudosos y han generado controversia, ${ }^{\text {s1 }}$ la ley permitía al acreedor apoderarse de los bienes del deudor que compensaran la deuda y en el caso de que este opusiera resistencia, el acreedor podía llevarlo juicio en una acción conocida como dike exoules ${ }^{52}$ que si la ganaba conllevaba no solo el pago al acreedor sino una multa igual al Estado. Si esta multa no era satisfecha, el deudor era también deudor público y por tanto un atimos. ${ }^{53}$ Además, si la propiedad que se reclamaba era un bien mueble el acusador podía solicitar al demandado que tenía el objeto dispu-

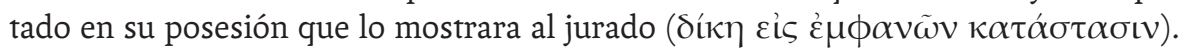
Si no lo enseñaba, no solo perdía esa propiedad, sino que se le imponía una multa

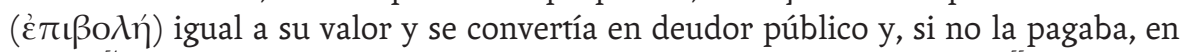
atimos. ${ }^{54}$ Generalmente cuando se producía un juicio privado por deudas ${ }^{55}$ o por cualquier otra cuestión, el caso había pasado en primer lugar por los "cuarenta" (treinta en el siglo V) o jueces por demos, que resolvían hasta un importe de 10 dracmas y, si no había acuerdo, por un árbitro (diaitetai) de más de 60 años, que debía preparar el

49 Para la propiedad confiscada, disponible para la venta pública por los poletai, ver el procedimiento en nota 25.

5o MacDowell (1978, pp. 142-147) distingue distintos tipos de juicios por deudas privadas dependiendo de lo que se debiera, como, por ejemplo: dike enoikiou (alquiler de casa) y dike karpou (que muestra que se paga en especie), dike ousias (propiedad), dike argyriou (efectivo), dike khreos (deuda), y casos de esclavos y animales, etc. Ver también Harrison (1968, pp. 222-227) (dikai ousias, karpou, enoikiou); cf. Harp. (= Phot, art. 2 = Sud, art. 2 = Anecd. Bekk, 285) s.v. ousias dike. Ver también Arist. [Ath. Pol.] 52.2 (con la figura del eisagoges introducida en el siglo IV). Vamos a analizar más extensamente estas cuestiones relativas a las deudas privadas en otro artículo próximamente.

51 En el artículo citado, Hansen (1982) discute cuatro posibles casos en los que por una deuda privada podría de-

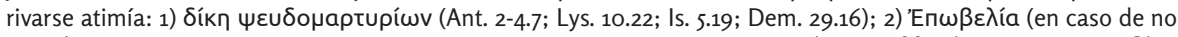

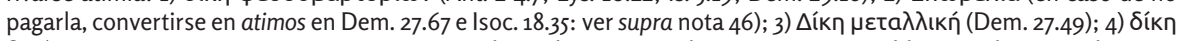
ßıaíwv (?) (Isoc. 16.46-57). Hansen termina concluyendo que, en todos estos casos, posiblemente la atimía derivaría de multas pagaderas al Estado que se sumaban a la multa debida al ganador del litigio.

52 Christ (1998, p. 532). Aunque se conoce algún caso de dike exoules antes incluso de intentar apropiarse de la deuda: Dem. 21.80-81. Para dike exoules ver: Harrison (1968, pp. 217-221, 311-312); MacDowell (1978, pp. 153-154) quien señala que una persona que, al ganar otro caso, hubiera sido indemnizada pero no hubiera recibido el pago de la indemnización por parte de su oponente dentro del plazo previsto, también podría interponer un dike exoules contra él; es el caso de Demóstenes contra Midias: Dem. 21.44, 81 (ver también Dem. 52.16; Harp. s.v. exoules). Para dike exoules ver recientemente ver Carey (2018), con referencia a las distintas modalidades y posibles tipos de casos. El papiro de Oxirrinco (P. Oxy. 2537: Carey fr. 308) menciona cinco discursos de Lisias en casos de dikai exoules del periodo posterior al 403: Rubinstein (2018, p. 14, n. 24). La apropiación o intento de apropiación de los bienes de otro por deuda debía de ser relativamente frecuente pues la ley prohíbe el cobro de deudas durante varios festivales (Dem. 21.10) probablemente para evitar no solo interrupciones en las fiestas, sino también incautaciones por sorpresa en casa de los deudores cuando estaban fuera en un ritual. Christ (1998, p. 532).

53 El que pierde dike exoules se le impone una multa al Estado: Oxyrhynchus Papyri 221 col. xiv 10-15; And. 1.73, Isae. 5.22-24; Dem. 21.44. MacDowell (1978, pp. 153-154); Carey (2018).

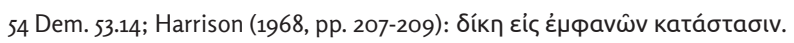

55 Ver nota 49.

56 Arist. [Ath. Pol.] 53.1-2; Harrison (1971, pp. 18-21). 
caso para el tribunal y si era posible poner de acuerdo a los litigantes antes de llegar a juicio (Arist. [Ath.Pol.] 53.2-6). ${ }^{57}$ Cualquiera de los litigantes podía recurrir a juicio si no estaba de acuerdo. El árbitro, por su trabajo, se llevaba, como mínimo, una dracma de cada litigante. ${ }^{58}$ Si el importe adeudado no superaba las 200 dracmas se convocaba un tribunal de 201 miembros, pero si superaba esta cantidad podía llegar a ser de 401 (Arist. [Ath. Pol.] 53.3; Poll. 8.48). ${ }^{59}$ En la segunda mitad del siglo IV se establecieron también los eisagogeis (Arist. [Ath. Pol.] 52.2) para aliviar a otros magistrados en un cierto número de juicios en los que se garantizaba el privilegio de una decisión en 30 días. Estos magistrados trataban litigios relacionados con el impago de la dote, por préstamos no devueltos con interés de una dracma, por préstamos para comerciar en el mercado, los procesos por ultraje, por préstamos de amistad (eranikas) y entre asociados (koinonikas), los de esclavos y bestias y los referentes a la trierarquía y la banca. Estos casos no iban a los árbitros, sino que decidían ellos si pasaba a tribunal

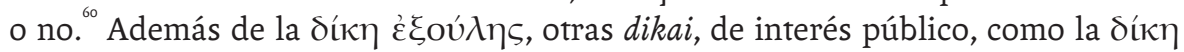

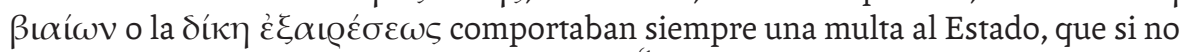
se pagaba convertía en atimos al condenado. ${ }^{61}$ Similar era el caso de la multa como

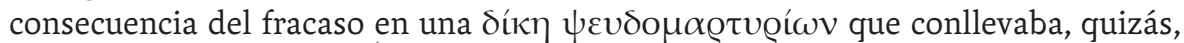
como argumentó Hansen, ${ }^{62}$ el pago de una multa al Estado, por tratarse de una dike en un juicio ante un tribunal de 500 miembros como las acciones públicas ordinarias.

Por último, si uno planteaba una graphe, citada también en el resumen de Andócides

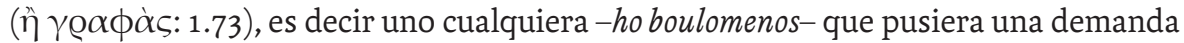
por un asunto de interés público y no continuaba con el proceso o no conseguía la aprobación a su moción de un quinto de los votos del jurado, se le imponía una multa de 1.000 dracmas a pagar al Estado y la atimía parcial y si no era satisfecha la deuda,

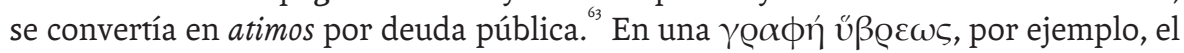
demandado, si perdía, debía pagar una multa al vencedor del litigio y la misma cantidad al Estado, multa que si no era satisfecha implicaba atimía por deudas (además de prisión). ${ }^{64}$ En otros casos, como en casos de eisangelia o probole, la Heliea podía poner como pena al acusado una multa pagadera al Estado que si no era satisfecha conllevaba atimía. ${ }^{65}$ Por otra parte, también en los casos de phasis o denuncias, entre

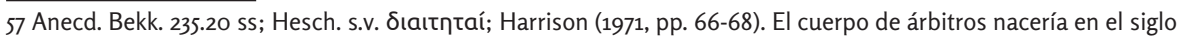
IV, mientras que en el siglo $V$ serían los magistrados los que arbitraban: Allen (2000, pp. 42, 322).

58 Aunque podía ser más (una dracma adicional por cada día que se prolongue la vista): Thür (2015, p. 37).

59 Allen (2000, p. 46): los tribunales de 500 miembros en adelante estaban, en general, reservados para las graphai. 60 Harrison (1971, pp. 21-23). Para árbitros: Harrison (1971, pp. 64-68).

61 Harrison, 1968, pp. 217-222 (para dike exairesos; Dem. 58.21), pp. 311-314 (dike exoules); Harrison, 1971, pp. 78, 168 (dike biaion: Dem. 21.44; Harp. s.v. ßıaíwv). Carey, 2018, pp. 88 (dike exaireseos), 90 (dike biaion).

62 Hansen (1982, pp. 113-115).

63 Harrison (1971, p. 83); podía plantear una graphe cualquiera salvo los que "estaban fuera”: Dem. 21. 47; Dem. 24, 63; Dem. 59, 16, 52; Aeschin, 1.32. Existía un riesgo económico, por tanto, en las graphai, que debía impeler a no usar este sistema arbitrariamente, sobre todo para los pobres: Dem. 22.25-27; Osborne (1985, pp. 42-43). Este riesgo de incurrir en multa si no se llegaba a un quinto de los votos no ocurría con la eisangelía: Harrison (1971, p. 51), aunque esto cambió desde el 331 a. C.: García Domingo (2015, pp. 94-95); para este procedimiento ver recientemente Loddo (2019).

64 Dem. 21.44-45. Prisión hasta que se pagara la multa: Dem. 22.34. Para los casos que requerían prisión: Harrison (1971, pp. 242-243); generalmente los que llevaban retraso en los pagos de los derechos de recolección de tasas, derechos de minas y compra de bienes confiscados, pero también los sujetos a endeixis por incumplir las normas para los deudores públicos; asimismo se prescribía prisión para los convictos y multados por algunas ofensas (como үpa甲ń

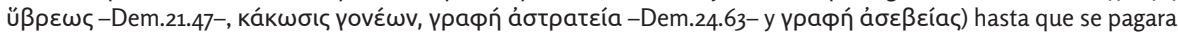
la multa, pero en algunos casos se podía dar nombres de garantes que aseguraran el pago (como en el caso por ase-


convicto hasta que pagara la deuda (conectado con el hecho de que podía ser extranjero y partir de Atenas), en este caso privada: Harrison, 1971, p. 188 (Dem. 33.1). También un demandante que tenía que pagar epobelía (ver nota 46) por perder el caso podía estar sujeto a prisión hasta que pagara: Dem. 35.46; Dem. 56; Harrison (1971, p. 188). Ver también Hunter (2000, pp. 28, 33-34).

65 En el caso de eisangelia era encarcelado hasta que pagara: Harrison (1971, p. 56). Dem. 24.63. Pena pecuniaria en casos de probolai como es el caso de Milcíades, por su gestión en Paros, condenado a una pena pecuniaria de 50 talentos: Hdt. 6.13; también, posiblemente, el caso de Agoratos, condenado a pagar 10.00o dracmas: Lys. 13.65; Harrison (1971, pp. 6o-62). En una probole se elegía la pena después de ser condenado el demandado: Harrison 
otras cosas, por desenterrar olivos del Ática (Dem. 43.71), el demandado, si perdía, debía al Estado 100 dracmas por cada olivo y la misma cantidad al demandante; ${ }^{66}$ si no pagaba al Estado se convertía en atimos. También en el caso de juicio público (graphe) en el que se condenaba a una mujer extranjera por convivir como esposa legítima de una ateniense, este era multado con 1.000 dracmas debidas al Estado (y la mujer era vendida como esclava); además, por la misma ley, un ateniense que daba en matrimonio a una joven como si fuera ciudadana sin serlo, siendo extranjera, era procesado y si era condenado sufría atimía, sus bienes eran confiscados y un tercio de estos iba a parar al acusador. ${ }^{67}$

De este modo, aunque las pequeñas deudas y los préstamos "sin intereses" entre vecinos o familiares se dirimirían habitualmente en acuerdos privados y se procuraba no llegar a los tribunales, está claro que, en ocasiones, y quizás con frecuencia, como muestran las Nubes de Aristófanes, esto ocurría y si no había fondos suficientes para pagar las costas si se perdía el juicio, o se llegaba a una dike exoules, el deudor privado, al ser también deudor público, se convertía en atimos. Otro tipo de juicios como las graphai conllevaban asimismo riesgos en este sentido si eran emprendidos por gentes de pocos recursos, pues no llegar al mínimo requerido de votos comportaba una multa al Estado muy importante, difícil de satisfacer por un pequeño o mediano propietario (lo que evitaría, también, la proliferación de este tipo de juicios); los denunciados en una graphe eran sometidos a multas pagaderas al Estado y a otras penas si perdían el juicio. De este modo, las multas impuestas por magistrados, por la boule o por tribunales podían terminar en deuda pública y por tanto en atimía y, por lo que se deduce de Aristófanes, esto debía de ser bastante frecuente; a ello hay que sumar los costes de los juicios que, aunque pequeños, en los casos de deuda se sumaban (los propios y los del contendiente vencedor) a la deuda ya existente. Todo ello lleva a considerar la posibilidad de un amplio abanico de miembros del demos de distinta posición socioeconómica susceptibles de caer en atimía por deudas.

\section{Pérdida de derechos de los atimoi}

Los atimoi en Atenas clásica habían perdido los privilegios de la ciudadanía, como ir a la asamblea, proponer decretos, servir como jueces, actuar como denunciantes en juicios privados y públicos, dar testimonio en tribunales, desempeñar magistraturas, entrar en el ágora y en santuarios; sin embargo, no perdían la condición de atenienses

\footnotetext{
(1971, p. 63)
}

66 Harrison (1971, pp. 218-221); Dem. 43.71. En caso de perder, el ciudadano que había planteado la acción podría estar sometido a epobelía (ver nota 46). Otros casos que podían llevar a esta acción legal eran: protección de huérfanos (Harrison, 1968, pp. 115-117), apropiación indebida de propiedad estatal (IG II2 30 fr. a, lin. 6 (386/5); Isoc 18. 5; Harp. s.v. Фáбıc; Poll. 1.47; Anecd. Bekk313.20 ss) o por explotación de minas fuera del área concedida por contrato por los poletai (Hyp. 3.5; Dem. 37.35; Poll. I. 47; Anecd. Bekk. 315.16 ss. Phot. s.v. Фáбıc); daños a edificios o tierra pública (Anecd. Bekk. 315.16 ss; Phot, s.v. Фá бıc) y finalmente préstamo por parte de un ciudadano ateniense o un meteco a un barco que no estaba destinado a traer grano a Atenas (Dem. 35.51) o, enjuiciamiento de alguien que, residiendo en Atenas, envía grano a cualquier destino que no sea Atenas (Dem.58.5 ss; Dem. 34.37; Dem. 35.59; Lycurg. Leoc. 27; Anecd. Bekk. 313.20 ss); también están contempladas infracciones más generales de los reglamentos de importación y exportación (IG I2 45) y algunos actos de impiedad (Dem. 22.27); Harrison (1971, p. 219). Para phasis ver también: Osborne (1985, pp. 44, 47-48).

67 Dem. 59.16. Harrison (1968, pp. 26-27); posiblemente leyes de época de Pericles cercanas a la ley de ciudadanía: Osborne (1985, p. 44; 2010, p. 178).

68 Ar. Nu. 30 ss, 117, 240-242, 739, 752 ss, 1131 ss. Tema de la deuda acuciante también en Asambleístas: Ar. Eccl. 567 y $655-58,567,659$.

69 Un caso conocido de un atimos que no puede testificar en un juicio es el de Estratón de Falero que ejerció de árbitro entre Demóstenes y Midias y al que este personaje, rico e influyente, consiguió que procesaran y condenaran los árbitros (Arist. [Ath. Pol.] 53.6) después de ejercer como árbitro y quedó como atimos, ya mayor (más de 6o años) y con pocos medios: Dem. 21.87, 90, 95 (пźvп५). Harris (2013, pp. 231-232). 
ni de astoi y parece que no se les borraba del demo o de la fratría, ${ }^{70}$ aunque podían ser vulnerables al ataque no solo en su propiedad sino también en sus personas. ${ }^{71}$ En algunas circunstancias se podía imponer la prisión a algunos deudores del Estado, ${ }^{72}$ también vigente si se violaban las restricciones de la atimía. ${ }^{73}$ Los atimoi tampoco podían entrar en el ágora ni participar de la vida religiosa (hiera kai hosia), que formaba parte de las timai de la ciudad. ${ }^{74}$ Tenían prohibido acceder a los santuarios y participar del culto público.

La condición de atimos en Atenas debía de ser dura y difícil. Según el joven Alcibíades, en Isócrates (16.47), "es un destino mucho más miserable vivir entre conciudadanos privados de derechos cívicos que vivir como un extranjero entre extranjeros". En Lisias, En favor del soldado, Polieno, acusado en apographe, prefiere el exilio (sin duda, una exageración) a permanecer como atimos sin derechos en Atenas (Lys. 9.21). En Demóstenes (24.201) se alude también a la situación penosa del padre de Timócrates,

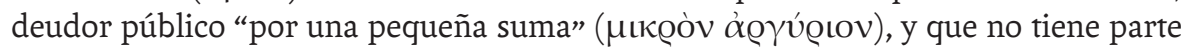
en la ciudadanía y cuya situación se califica de horrible y digna de compasión (oú $\tau^{\prime}$

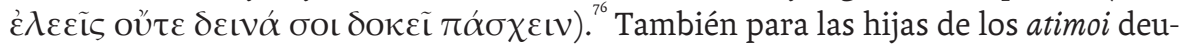
dores la situación era complicada pues se hacía muy difícil casarlas legítimamente (Dem. 59.8). ${ }^{77}$ La deuda debía de ser bastante frecuente, como testimonia Aristófanes a finales del siglo V y a inicios del siglo IV $^{78}$ y, en muchos casos, el procedimiento podría terminar con una dike exoules y los inculpados podían resultar atimoi, también por cualquier otra multa impuesta en un juicio o por un magistrado y que no pudiera pagarse por falta de recursos.

¿De qué vivían o a qué se dedicaban los atimoi despojados de sus propiedades y que seguían viviendo, ellos y sus hijos ${ }^{79}$-que heredaban esta condición- en el Ática? En muchas ocasiones, podemos suponer que se recurría a parientes o amigos ricos (también en principio para intentar saldar la deuda). En el caso de no conseguir devolver lo adeudado o incluso, también, después de pagar (para los que hubieran recibido un "préstamo" de un pariente o amigo rico), podrían darse situaciones de trabajo para ellos, en relaciones desiguales, lo que siempre era una degradación. ${ }^{80}$ Estas circunstancias se producirían en el marco del establecimiento de "obligaciones" con distintas formas de trabajo y prestaciones, tanto productivas como políticas, que se dan en las relaciones de charis (favores) y de "agradecimiento". Se crean dependencias a partir de una obligatoriedad "moral" de devolver la deuda, como se tiene

70 Sch. Aeschin. 3.176. Harrison (1971, p. 83); Hansen (1976, pp. 61-63); Poddighe (2006, pp. 13-14); Kamen (2013, p. 79). Wallace (1998, p. 72).

71 Harrison (1971, p. 83). Hansen (1976, p. 55-61). Ver Lys. 6.24; Isae. 10.20; Dem. 21.87 (ver nota 68). En Gorgias (486bc; 508c-d) Platón sugiere que incluso en su época los atimoi podían ser abusados con impunidad, despojados de sus propiedades, enviados al exilio o incluso muertos; este sentido está más en consonancia con el de proscrito (Dmitriev, 2015), que para Youni (2018) es una pena distinta a la atimía; ver, sin embargo, esta autora (2001) para las expresiones de atimos tethnato o atimos esto+pheugein y Maffi (2018). Ver Manville (1980, pp. 214-216).

72 Ver más arriba nota 63; Arist. [Ath. Pol.] 48.1; Dem. 24.39-40; Kamen (2013, p. 77, n. 22).

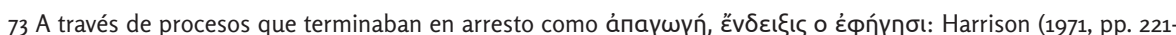
232). Estudiado en detalle por Hansen (1976, pp. 9-35, 90-98). Ver Kamen (2013, p. 77). Para endeixis ver discurso 58 de Pseudo-Demóstenes (Contra Teocrines): 58.14 (es acusado de actuar como epitimos aunque es un deudor del Estado: Dem. 58.5-21)

74 Para estas cuestiones: Blok (2017).

75 Aeschin. 3.176; Lys. 6.9, 24; Kamen (2013, pp. 77-79).

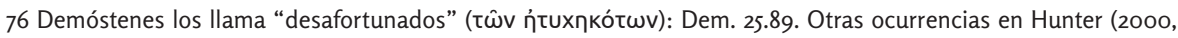
p. 34).

77 Hunter (2000, pp. 29-30): una epikleros podría heredar, como el varón, la deuda de su padre.

78 Ver nota 67

79 Los deudores del Estado eran los únicos atimoi que podían dar sus hijos en adopción para ahorrares la carga de la atimía: Kamen (2013, p. 78). Atimía hereditaria: ver supra nota 23.

8 o El caso de Eutero, antiguo cleruco sin propiedades después de la guerra, contado por Sócrates: Xen. Mem. 2. 8. 1-5. 
constatado especialmente en el siglo IV. ${ }^{81}$ Así, por ejemplo, Jenofonte puede decir en el Recuerdos de Sócrates (2.10.2-4):

Y si algunos de tus conocidos, que es mucho más útil que tus esclavos, corre el peligro de perecer a causa de la necesidad ( $\varepsilon^{\prime} v \delta \varepsilon\llcorner\alpha v)$, ¿no crees que merece la pena que te preocupes para salvarlo? Pues bien, tú sabes que Hermógenes es un hombre inteligente y se avergonzaría, en el caso de ser favorecido por ti, de no corresponder a tus favores. Aunque tener un colaborador espontáneo, leal, constante, dispuesto a hacer no sólo lo que se le mande sino capaz de ser útil por propia iniciativa, de prevenir y de prever, creo que equivaldría a tener muchos esclavos. Los buenos administradores dicen que cuando se puede comprar a buen precio algo de mucho valor es cuando hay que comprarlo. Ahora mismo, en estos tiempos que corren, se pueden comprar buenos "amigos" (comillas mías) a muy buen precio". 82

Las deudas se plantean, sobre todo en textos del siglo IV, como fuente de miserias. En la República (555C-E) de Platón se habla de aquellos empobrecidos "que andan en el país sin hacer nada, provistos de aguijón y bien armados, unos cargados de deudas, otros privados de derechos políticos, otros de las dos cosas; y odian y conspiran contra los que poseen patrimonio propio y contra los demás, anhelando una revolución"." Cuando habla de "cargados de deudas, otros privados de derechos políticos y otros de las dos cosas" se refiere, en este último caso, sin duda, a deudores públicos cuyo impago de la deuda comportaba la atimía. Aunque en esta referencia concreta el interés de Platón es resaltar la vida de jóvenes ricos licenciosos que se han endeudado y han perdido su patrimonio, sin duda también esta situación podría referirse a gentes menos pudientes del demos, como se desprende de otras fuentes. ${ }^{84}$ La alternativa para los pobres, tal como plantea Isócrates (Areopagítico), y en este caso, podemos imaginar que para los deudores sin propiedades o atimoi, sería el contratarse como asalariado/ jornalero -en el mejor de los casos como capataz- o como arrendatario en tierras privadas (o en otros negocios: artesanos, por ejemplo) en condiciones precarias.

Los atimoi se asemejan en el imaginario y se igualan a aliados extranjeros, metecos e incluso esclavos. ${ }^{86}$ Ellos y sus hijos permanecen en esa condición hasta pagar la deuda y su condición se hereda igual que la pérdida de propiedades que resultan confiscadas por el Estado. Aunque el atimos que permanecía en el Ática, es decir el

81 Ver especialmente los trabajos en este sentido de Plácido (2006; 2008; 2012; 2017) y Plácido-Fornis (2011).

82 También en Xen. Mem. 2.1.12-13; 2.4.1. Algo similar en Arist. Eth. Nic. 1162b: “La amistad ética, por otra parte, no se basa en especulaciones, sino que otorga un regalo, o cualquier otra cosa, como a un amigo, pero el dador considera justo recibir otro tanto o más, como si no hubiera dado, sino prestado, y si las condiciones en que hizo el convenio no son las mismas al disolverse, reclamará”. 1163b: “Así, también debe uno comportarse entre desiguales, y el que es favorecido con dinero o con virtud debe corresponder con honor, pagando con lo que puede” (Traducción de Pallí Bonet, 1985). Ver los trabajos de Plácido en nota anterior.

83 Plat. Rep. (555C-E). Traducción de Eggers Lan (1988).

84 También, en la misma obra, se resalta "el permitir a uno vender todo lo suyo y a otro adquirirlo, y al que ha vendido vivir en el Estado sin pertenecer a ningún sector del Estado no siendo negociante ni artesano, caballero ni hoplita, a simple título de pobre e indigente": Plat. Rep. 549E y 552A. Para endeudamiento en el s.IV ver las Asambleístas de Aristófanes en nota 67. Ver Valdés (2015, 2018).

85 Isoc. Plataico (14), 48. Los pobres tienen vetado, en líneas generales (aunque con excepciones), el arrendamiento de tierras públicas, por lo que arrendarían tierras privadas en condiciones desfavorables (Osborne, 1988, pp. 318, 322; Paiaro, 2008, p. 218), y preferirían "esta opción antes que cambiar de modo de vida o emigrar a la ciudad, e incluso que contratarse como bracero en el campo de otro (Osborne, 1988, p. 319)": Valdés (2015, p. 189). Retoma el tema, recientemente, proponiendo la frecuencia del arrendamiento en época clásica (mediante acuerdos orales, con testigos, lo que no deja huella en el registro): Paiaro (2020). No hay que descartar, en cualquier caso, tampoco, la posibilidad de arriendo de tierras o propiedades públicas en ocasiones a gentes con pocos recursos, como, quizás, en el Pireo (IG II2 2498: por debajo de 10 dracmas).

86 Considerados como xenoi cuyas ciudades no tuvieran tratado con Atenas: Harrison (1971, p. 83). Los deudores públicos aparecen como estigmatizados en Cratino (fr. 333 Kock -sch. Lucian, Zeus Trag. 48-), y, por tanto, como similares a los esclavos que estaban marcados por el fuego y eran estigmatizados: Hunter (1992, pp. 281-282); Finley (1980, p. 95); Holmes (2010); Halm-Tisserant (2013, pp. $43-44$ y 120-121). Extranjero, esclavo y átimos en el mismo plan: Mactoux (1980, p. 61). Para la prohibición de entrar en el ágora y en lugares sagrados para el atimos así como para las duras condiciones de la atimía en el Gorgias de Platón ver nota 70. 
que derivaba la atimía de deudas u otros delitos como los especificados más arriba, total o parcialmente, no podía ser víctima de maltrato sobre su persona y, a diferencia de los atimoi en tiempos previos a Solón, habitualmente no era agredido, ${ }^{87} \mathrm{ni}$ mucho menos vendido como esclavo o muerto, sí constituía un deshonor vivir en esa situación, pues veían seriamente limitados sus derechos en el ámbito político y judicial. ${ }^{88}$ Sobre todo, aquellos que habían sido despojados de sus propiedades y, además, partían de medios modestos, les sería prácticamente imposible recobrar la ciudadanía plena por ley salvo en caso de amnistía. Sin embargo, posiblemente no siempre se cumplía la ley a rajatabla como atestigua Demóstenes, pues había atimoi y, sobre todo, descendientes de atimoi, que seguían ejerciendo sus derechos cívicos, aunque se arriesgaban a ser arrestados y a un juicio. Esto ocurriría, sobre todo, con atimoi "automáticos", como es el caso de los deudores; sin duda podría haber pequeños deudores que debían las costas judiciales o alguna multa impuesta por un magistrado o tribunal y que tratarían de pasar desapercibidos, aunque se arriesgaban a ser denunciados por otros. ${ }^{90}$ En última instancia, el control dependía, en gran medida, de los propios conciudadanos. ${ }^{91}$ En muchas ocasiones cabe suponer que los atenienses, aun sabiendo de la condición de deudores (por pequeñas multas, etc.) de otros conciudadanos, harían la "vista gorda". Aun así, existiría el peligro real de ser denunciado por rencillas personales y venganza, entre otras cosas. Es el caso, por ejemplo, de un tal Pirro, en el discurso del Contra Midias de Demóstenes, que sirvió como juez por pobreza, para cobrar los tres óbolos, y fue condenado y ejecutado por su ofensa pues era atimos y no podía ejercer ese derecho. ${ }^{93}$

\section{Rehabilitación de atimoi y demografía}

No se conoce el número de atimoi pero tuvo que ser realmente significativo pues en periodos de crisis social, política, militar y demográfica se condonó la deuda ${ }^{94}$ y se propició la reintegración de atimoi en la ciudadanía, para hacer frente a determinados peligros. Ya en época arcaica se puso en funcionamiento una ley de epitimia para reivindicar a los que habían caído en atimía, posiblemente, en este caso, por deudas tanto públicas como privadas, abarcando, por tanto, a un colectivo muy amplio. En esos momentos la ley de atimía posiblemente formó parte de la Seisachtheia y se utilizó

87 Sí podía ser víctima de la violencia o de agresión cuando incumplía las condiciones de atimía, similar a lo que ocurría con las mujeres adúlteras que entraban en lugares sacros que podían ser agredidas o maltratadas, aunque no podían ser muertas ni mutiladas (Aeschin, 1.183; Dem., 59.87). Para la violencia frente a endeudados atimoi en época de Solón: Valdés (2019a). Para desprotección de atimoi también en época clásica. Hansen (1976, pp. 56-58).

88 Los atimoi, en cualquier caso, mantenían sus derechos de matrimonio y herencia pues siguen siendo todavía atenienses: Poddighe (2006, p. 13); Kamen (2013, p. 77). Sin embargo, sus derechos estaban muy limitados porque no podían reclamar en los tribunales (los atimoi parciales solo perdían el derecho de iniciar graphai pero no posiblemente dikai) una herencia, por ejemplo, o una injusticia en ese ámbito: ver nota anterior. También estarían recortados sus derechos en juicios como kyrioi (con sus mujeres e hijos): Hansen (1976, p. 63).

89 Sería el caso de Teocrines, según su acusador, deudor del Estado por tres causas, en el discurso pseudo-demosténico 58 (Dem. 58.15). También podrían darse confusiones de nombres, sobre todo en lo concerniente a los antepasados deudores (Dem. 58.16-17); casos de sobornos para no llegar a ser inscrito en la acrópolis como deudor: Dem. 58.19. Posibilidad de ignorar la condición de atimia: Hansen (1976, pp. 59-6o, con notas 22-23); Wallace (1998, pp. 67, 77). Para juicios por incumplimiento de atimía ver nota 63.

90 Hacer "la vista gorda” en relación con atimoi que se comportan como epitimoi es una tendencia evidente, sobre todo con los deudores públicos (Dem. 35.85-91): ver nota anterior. Sin embargo, había riesgo de endeixis o apagoge: ver infra, nota 92, para el caso de Pirro.

91 La vigilancia sobre los mismos partiría de sus propios conciudadanos. Hunter (2000, pp. 35-37), quien señala lo difícil que sería el control estatal de los deudores públicos; Kamen (2013, p. 79). Muchos (ellos y sus hijos) pasarían desapercibidos, pero siempre correrían el riesgo de una denuncia si participaban en la vida pública.

92 Cf. Dem. 25.89. Hansen (1976, p. 59); Hunter (2000, p. 34).

93 Dem. 21.182. Hansen (1976, p. 6o).

94 No solo recuperan sus derechos, sino que sus deudas quedan canceladas: Hansen (1976, p. 87).

95 También podía darse de manera particular el indulto a algún atimos por deudas, pero requería el voto de 6.000 ciudadanos en la asamblea: Dem. 24.45. Poddighe (2006, p. 14); Kamen (2013, p. 78). 
para reintegrar a los deudores, cancelando las deudas, y ampliando significativamente el cuerpo cívico con los atenienses que habían ido cayendo en una "theteia"." Estas reintegraciones en época clásica ocurrieron en varios momentos. Aquí dejaremos de lado la amnistía del 404 y la del 403 pues, por la situación política, requieren un estudio aparte, ${ }^{97}$ y nos centraremos en la de Maratón, ${ }^{98}$ en la más conocida del 405, con la ley de Patroclides, ${ }^{91}$ al final de la Guerra del Peloponeso, después de Egospótamos -en momentos de una crisis demográfica, social y militar acuciante-y, finalmente, en situación, asimismo, de emergencia, tras Queronea, a propuesta del orador Hiperides. ${ }^{100}$ En este caso se suman los atimoi a otros colectivos excluidos de la ciudadanía o desclasados, como metecos, esclavos o expulsados de la ciudadanía con el diapsephismos del $346 .^{101}$ También a finales del siglo V la integración de los atimoi en el 405 coincide con un periodo en el que se llevó a cabo o, al menos, se planteó, la integración de metecos e incluso de esclavos en determinadas circunstancias como en las Arginusas, ${ }^{102}$ con la integración de los samios ${ }^{103}$-como se había hecho antes con los plateos ${ }^{104}$ o en la lucha contra los tiranos con Trasibulo. ${ }^{105}$ En Aristófanes, en torno a los acontecimientos del final de la Guerra del Peloponeso, parece que se percibe una corriente que reivindicaba la integración de los atimoi-especialmente, deudores-, que finalmente se llevó a cabo con Patroclides. Los atimoi se asimilan o acercan a otros colectivos como aliados extranjeros y metecos, e incluso esclavos, sin dejar de lado tampoco a colonos o hijos de colonos atenienses. Esta tendencia aparece claramente en Lisistrata donde se alude, de forma explícita a los "deudores públicos", en nuestra opinión el grupo de atimoi más numeroso en Atenas:

Cardar después en un canastillo la buena voluntad común, mezclando a todos los que

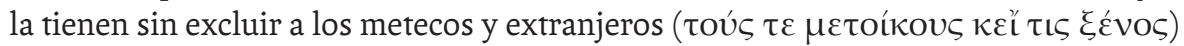
que nos quieren bien y mezclar también allí a los que tienen deudas con el tesoro

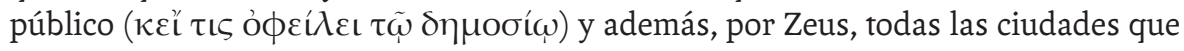

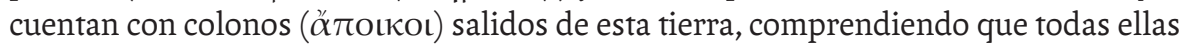
son para nosotros como mechones de lana esparcidos por el suelo cada cual por su lado. Y luego, cogiendo de todos ellos un hilo, reunirlos y juntarlos aquí y hacer con ellos un ovillo enorme y tejer de él un manto para el pueblo. ${ }^{106}$

96 Ver Valdés (2007) y próximamente: Valdés, “Atimoi and agogimoi. Reflections on debt slavery in archaic Athens”. Para theteia de atenienses antes de Solón: Diog. Laert. 1.45, 66. Ley de atimía en relación con la Seisachtheia: Rhodes (1981, p. 111); Rihll (1991).

97 Ver supra nota 2.

98 And. 1.77, 106-109.

99 Ver supra nota 21 e infra en el texto.

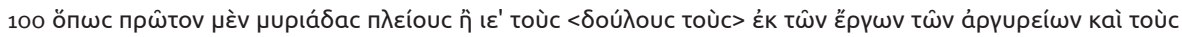

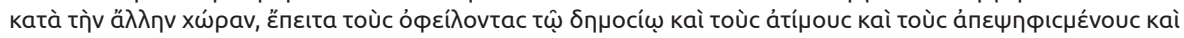

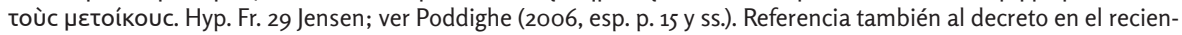
temente hallado discurso "Contra Diondas": Fr. 174r, lin. 30-33 (Carey et al., 2008, p. 19): "me acusaba por proponer que los esclavos que lucharon al lado del pueblo quedasen en libertad, en defensa de las cosas que muchas veces hicieron nuestros antepasados" (traducción de Muñoz Flórez, 2011, p. 229, con comentario).

101 El diapsephismos del 346 está documentado en el Contra Timarco de Esquines (77 y 114-115), en Filócoro (FGrHist 328 F 52) y Androción (FGrHist 324 F 25). Ver Fantasia y Carusi (2004); Kapparis (2005, pp. 93-94); Poddighe (2006, p. 18); Lape (2010, p. 203 y. ss.); Kears (2013, p. 186 y ss.).

102 Para Arginusas: Xen. Hell. 1.6.24. Ar. Ra. 693-694. Esclavos naturalizados con los mismos derechos que plateos: Helánico FGrHist 4 F 25 = sch. Ar. Ra. 694; Hunt (2001). También metecos y extranjeros: Diod. Sic. 13.97.1; Justin 5.6.56 Ver Kears (2013, p. 172 y ss.).

103 Xen. Hell. 2.2.6; IG II2 1.

104 Dem. 59.104; Kears (2013, p. 166 y ss.). Para concesiones de ciudanía excepcionales a finales del siglo V, lo que suscita críticas: Hunt (2001, p. 367). Kamen (2009, pp. 53-54).

105 Arist. [Ath. Pol.] 40.1; Aeschin. 3.195. Rechazado porque parece que no había pasado por la Boule como era prescriptivo: Plut. X. Orat. 835f-836a; Rhodes (1981, pp. 474-477). Patterson (1981, p. 146). Decreto de integración de metecos que ayudaron en la caída de la Tiranía de los 30 , aunque bastante más restringido (entre 53 y 100 personas) en el 401: IG Il2 10; Kears (2013, pp. 163-166). Sancho (2004, p. 95).

106 Ar. Lys. 574-586 (Traducción de Macía Aparicio, 2007b). Lo que Lisístrata propone es rehabilitar en sus derechos a los deudores atimoi y hacer extensiva la ciudadanía a metecos y extranjeros, así como a los aliados de la liga y a los colonos de Atenas: Sommerstein (1990, pp. 183-184). Konstan (1995, pp. 56-57) lo considera una Utopía, aunque se 
También en las Aves de Aristófanes se alude a la integración en la ciudad de los pájaros fugitivos, extranjeros, esclavos y atimoi:

y si hay entre vosotros algún fugitivo marcado al rojo vivo, recibirá entre nosotros el nombre de francolín de vivos colores; y si hay uno que sea más frigio que Espíntaro, será aquí el pájaro frígilo, de la familia de Filemón; y si es un esclavo, y cario, como Ejecéstides, será entre nosotros abu...tarda y le saldrán muchos cofrades; y si el hijo de Pisias quiere entregar las puertas de la ciudad a los privados de derechos (atimoi), que sea la perdiz, perfecto retoño de su padre, porque entre nosotros no está mal visto que una perdiz huya. ${ }^{107}$

Podría postularse la existencia, por tanto, de una tendencia en el demos, dentro del ambiente de esos años, transmitida por Aristófanes (aunque no necesariamente compartida por él en todos sus postulados), ${ }^{108}$ que propondría la rehabilitación y/o integración ciudadana de atimoi, metecos y otros extranjeros (aliados), así como de colonos y sus descendientes (posiblemente, hijos de colonos de madre extranjera) ${ }^{109}$ e incluso esclavos. Esta corriente se acentuaría, especialmente, desde el desastre de Sicilia. Aunque metecos, xenoi, atimoi y esclavos son categorías y situaciones muy distintas, se agrupan en el imaginario de manera conjunta, pues todas tienen en común la exclusión. Pueden adivinarse necesidades militares y demográficas derivadas de una situación de guerra prolongada y con efectivos ciudadanos decrecientes y en crisis.

En mi opinión, no hay que confundir esta reivindicación con aquella otra, muy diferente en carácter y trasfondo, que promovía la rehabilitación de los atimoi condenados como consecuencia de causas políticas que, en cualquier caso, podría filtrarse también, especialmente en relación con los hermocópidas y los profanadores de los Misterios, en el pasaje de las Aves del 414. Esta otra tendencia, de carácter más oligárquico, se encuentra asimismo en Aristófanes, en las Ranas, por ejemplo, ${ }^{110}$ del 405, y atañe, sobre todo, a la cuestión del retorno de los exiliados de la oligarquía de 400 que tuvo lugar finalmente en el $404 \mathrm{y}$ en el 403, tema que hemos dejado deliberadamente de lado (aunque el asunto de los exiliados afectaba directamente a Andócides). Así, por ejemplo, en la parábasis de las Ranas se menciona:

Es de justicia que el coro sagrado recomiende y ensene lo mejor para la ciudad. Y lo primero que nos parece es que todos los ciudadanos deben ser iguales y que hay que acabar con los temores. Y si alguno erro, engañado por los manejos de Frínico, mi opinión es que es preciso que los que metieron la pata entonces puedan arrojar de si la culpa y liberarse de su error de otrora. Afirmo, además, que no debe haber

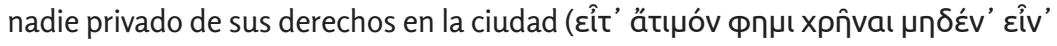
ह́v tก̣ nód $\varepsilon ı)$. Y es que resulta vergonzoso que unos que no han intervenido más que en un combate naval se hayan convertido al punto en plateenses y en señores en vez de esclavos. Y yo no podría decir que eso no esté bien, que lo aplaudo, porque es la única medida sensata que habéis aprobado; pero también es razonable que a estos, que-ellos y también sus padres-han librado ya muchas naumaquias a vuestro lado

presenta como defendida por las mujeres. Propuesta panhelénica: Vetter (2005, pp. 63-77). Ver también el análisis de Coscolla (200o), quien señala, asimismo, las necesidades militares del momento.

107 Ar. Av. 762-765 (Traducción de Macía Aparicio, 2007a). Es posible que el comediógrafo aluda aquí, también, especialmente a las víctimas de los procesos de la parodia de los Misterios y de la mutilación de los Hermes, pues la obra es de esa época (414).

108 Aristófanes puede reproducir, como, de hecho, hace en otras ocasiones, distintas corrientes de opinión que operaban en el demos de Atenas. Para una visión de lo que el propio Aristófanes defendería en relación con estas cuestiones: Coscolla (2000). Esta tendencia “integradora" pudo cobrar fuerza y ganar adeptos por motivos demográficos y militares al final de la guerra del Peloponeso.

109 Ver, en general, Valdés (2019b).

110 Ver comentario en Gallego (2012). 
y son de vuestra misma sangre les disculpéis esa única falta, si os lo piden. Vamos, deponed vuestra irritación vosotros que sois sapientísimos por naturaleza; hagamos de buen grado parientes, ciudadanos y dueños de derechos (kánıtífouc) a todos los hombres que alguna vez han luchado a nuestro lado en una naumaquia. Y si, por el contrario, nos damos importancia y nos mostramos demasiado orgullosos, y lo hacemos en un momento en que la ciudad se encuentra a merced de las olas, en el futuro parecerá que no hemos sido sensatos. ${ }^{111}$

La ley de Patroclides del 405, aunque rehabilitó a los soldados parcialmente atimoi que habían colaborado con el gobierno de los 400 (1.75) y que habían permanecido en Atenas, no parece que contemplase la venida de los exiliados (1.80). El hecho de que estos soldados (oí $\sigma \tau \varrho \alpha \tau \iota \tilde{\omega} \tau \alpha \iota$ ) fueran hoplitas, lleva a pensar que pesó más, en esos momentos, su capacidad militar que su posicionamiento político en la oligarquía, dada la situación de emergencia ante un posible asedio, con un gobierno todavía democrático antes de la rendición final frente a Esparta. La corriente integradora de los excluidos en situación de emergencia militar y demográfica, no es incompatible, por tanto, con otras tendencias, incluso dentro del demos (sobre todo "hoplítico"), desde postulados "moderados", que propondrían la venida de los exiliados y la reconciliación con ellos, como reivindica Aristófanes en las Ranas.

Los casos que estamos analizando en que los atimoi son reintegrados, posiblemente en forma "masiva" o numéricamente importante, se refieren a situaciones de guerra ${ }^{112}$ y de emergencia nacional que requieren el aumento poblacional de posibles luchadores o guerreros. Esto se suma, especialmente en el 405 a una crisis demográfica y ciudadana acuciante. ${ }^{113}$ La necesidad de efectivos militares tuvo lugar también en Maratón, frente a los persas, momento en el que los Atenienses quedaron solos (salvo los plateos) ante el enemigo, y tras Queronea, ante un posible asedio de Filipo, lo que llevó a la propuesta de Hiperides de dar la ciudadanía a los que lucharan. ${ }^{114}$ El decreto fue aprobado por la asamblea, pero finalmente no se aplicó por el pacto al que se llegó, después, con el rey macedonio. Hiperides fue llevado a juicio, en una graphe paranomon a propuesta de Aristogitón, pero salió absuelto del juicio, lo que, en cierto modo, indica, también, la popularidad de sus medidas integradoras en situación de crisis. ${ }^{115}$ En estas ocasiones, sin duda, la emergencia y la necesidad de efectivos jugaron un papel importante, sin que podamos descartar, como señalábamos más arriba, la existencia de tendencias o corrientes que veían con buenos ojos la integración de determinados sectores excluidos, como podrían ser los deudores y otros colectivos (apoikoi o, incluso, metecos), supuestamente dentro de una línea más democrática o democratizante, como la que ostentaría el propio Hiperides (y, en fechas anteriores, Trasibulo). Esta línea se fortalecería y ganaría adeptos por la situación militar de emergencia. El objetivo de ampliar el número de los combatientes conlleva, en cierto

111 Ar. Ra. 686 ss. (traducción de Macía Aparicio, 2007b). Coscolla (2000, p. 12 y ss.).

112 Kamen (2013, p. 80): podían recibir amnistía para luchar. MacDowell (1978, p. 74) piensa que no serían excluidos del servicio militar. Ver, sin embargo, Poddighe (2006, p. 11).

113 En esos momentos la población de Atenas (unos 25.000 y posiblemente menos) se habría reducido a menos de la mitad de la que había en 431: Hansen (1988, pp. 22-23, 26, 28).

114 Para la propuesta de Hiperides ver notas 13 y 99; Hiperides alude a esclavos, deudores públicos, atimoi, víctimas

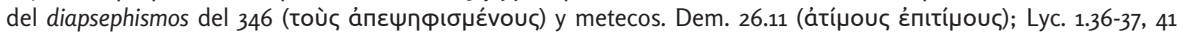
(extranjeros, esclavos y atimoi). Menciona la integración de esclavos: Dio Chris. 15. 21 (habla de oíkétaç no de douloi, lo que es interesante) y señala que se estipuló que los siervos que participaran en la guerra fueran liberados (źv

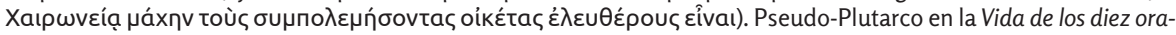
dores (Plut. Mor. 484f-489a) menciona a metecos y esclavos. Situación de emergencia: Lyc. 1.36. Poddighe (2006, p. 6 y ss.) cree que no hay que enmendar a los apoikoi que menciona la Suda en su referencia a Hiperides por "metecos"

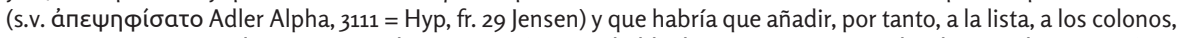
sin necesariamente excluir tampoco a los metecos (Licurgo habla de extranjeros y pseudo-Plutarco de metecos).

115 Su propuesta fue aprobada tanto en votación de la asamblea como, después, al quedar absuelto por el tribunal. Juicio: Plut, Mor. 849a. El orador se defiende en su discurso Contra Aristogitón (fragmentos 27-39 Jensen). Ver nota supra nota 99. 
modo, pensar que los deudores atimoi y los atimoi en general estarían excluidos de los catálogos de hoplitas, aunque posiblemente no eran borrados de las listas de los demos y fratrías y seguían siendo Athenaioi y astoi. ${ }^{116}$ Wallace cree, en efecto, que los

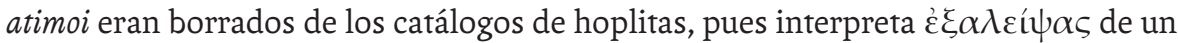
pasaje de Los caballeros de Aristófanes en este sentido. ${ }^{1.7}$ Tiene sentido que los atimoi estuvieran excluidos del servicio militar, pues las faltas graves en este terreno, como la deserción, conllevaban precisamente la pena de atimía, como vimos más arriba. ${ }^{1.8}$ El elemento militar y la coyuntura de emergencia total es, por tanto, un aspecto fundamental, para la rehabilitación de los atimoi-entre otros colectivos-, pero no puede descartarse que estas necesidades su sumaran a posiciones aperturistas, dentro de corrientes democráticas o "democratizantes" en la Atenas clásica.

Algo similar a lo acontecido en el 405 y en Queronea, ocurriría en Maratón. La amnistía de los atimoi en esos momentos está solo documentada por Andócides y plantea serios problemas. Por una parte, se menciona en el decreto mismo de Patroclides que se reproduce en el discurso (1.77) y que, como se ha señalado, podría ser una falsificación helenística. ${ }^{119}$ Aunque este fuera el caso, todavía podría considerarse la validez de la referencia para el conocimiento, en esas fechas, de una amnistía de atimoi en el 490, idéntica a la del 405, pues Andócides corrobora, más adelante en su discur-

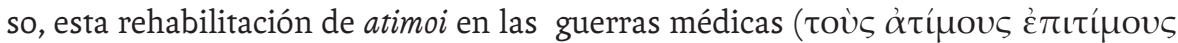
$\pi$ rotñ $\sigma \alpha$ s: And. 1.107, 109). La cuestión, en cualquier caso, se complica porque este autor, al mencionar la amnistía de los atimoi, la asocia con la restauración de derechos a los exiliados, algo que aparentemente no se dio en el 405, con Patroclides (And. 1.80). Andócides, en su discurso (1.107), alude de manera conjunta a los exiliados de Atenas afines a los Pisistrátidas que retornan a Atenas con las guerras médicas y a la amnistía a los atimoi que habían permanecido en Atenas ("acoger de nuevo a los exiliados y restablecer en sus derechos a quienes estaban privados de ellos en orden a promover unos comunes riesgos a la vez que una común salvación"). Sin embargo, Andócides comete un grave error y confunde la batalla de Maratón con el incendio de la ciudad en Salamina (1.108); por eso, quizás, en las alusiones a la amnistía mezcla de forma inexacta, como para el 405 (1.109), y posiblemente de forma deliberada (por su interés particular como exiliado), la reintegración de atimoi y la llegada de pheugontes, que no se habría producido en esos momentos (Maratón) sino más tarde, al menos para aquellos que estaban en el ostracismo, a los que se permite volver justo antes de Salamina. ${ }^{120}$ Es plausible, por tanto, postular, como hace Hansen, que en las vísperas de Maratón se decretara solo, como en el 405, una amnistía para los atimoi que habían permanecido en el Ática y no el retorno de los exiliados. A Andócides, como exiliado y atimos, le convenía crear confusión y confundir deliberadamente ambas situaciones (And. 1.109) de cara a su propia defensa. ${ }^{121}$ Aun así, no puede descartarse completamente que la amnistía del 490, en caso de considerarla histórica, comportara tanto la rehabilitación de los atimoi como la venida de los pheugontes. Al no tener otras fuentes para contrastar, la cuestión debe quedar necesariamente abierta. Por otra parte, Pausanias habla, para esos momentos (Maratón), de la liberación de esclavos para luchar, ${ }^{122}$ lo que no deja de tener un paralelismo destacado tanto con la situación

116 Poddighe (2006, p. 14). Ver nota 69.

117 Wallace (1998, p. 72); Ar. Eq. 876-880. Parece que en época clásica los atimoi no serían borrados de las listas de ciudadanos (del demo, fratría): ver nota anterior. En nuestra opinión en el arcaísmo, antes de Solón, la atimía sí conllevaría ser excluido de las fratrías, la instancia que permitía la entrada en la asamblea en esa época.

118 Ver nota 18.

119 Ver nota 12.

120 Arist. [Ath. Pol.] 22.8; Plut. Themist. 11.1; Plut. Aristid. 8.1.

121 Hansen (2015, pp. 896-897). Para los problemas de la amnistía de Maratón en Andócides: Canevaro-Harris (20162017, p. 17).

122 Paus. 7.15.7. Pausanias menciona a esclavos en Maratón también en 1.32.3 y en 10.20.2, pero no especifica que fueran liberados. 
del final de la guerra del Peloponeso (Arginusas y decreto de Patroclides, además de la propuesta de Trasibulo), como con la propuesta de Hiperides de liberación de esclavos que él mismo defiende, en el contra Diondas, que "muchas veces hicieron nuestros antepasados". ${ }^{123}$ Según Andócides (1.106) los atimoi en esos momentos serían aquellos afines al gobierno de los tiranos a los que no se había condenado a muerte $o$ expulsado después de la caída de la tiranía, sino que habían permanecido en Atenas, aunque sin derechos cívicos. Entre ellos seguramente podría haber seguidores del tirano salidos del demos, miembros de su guardia que permanecieron en la ciudad como atimoi y que pudieron tener un componente popular importante. ${ }^{124}$ Tampoco puede descartarse que el grupo de atimoi del Ática lo engrosaran, además, deudores públicos, entre los que podría haber, como señalábamos más arriba, gentes de condición modesta que, por multas y pequeñas deudas, terminaran, de un modo u otro, siendo deudores públicos y por tanto atimoi. En este contexto merece la pena recordar, también, para imaginar el perfil de estos pequeños deudores, los "préstamos a bajo interés" del tirano a gentes pobres (aporoi) a través de los jueces por demos, ${ }^{125}$ que teóricamente conllevarían atimía si no eran satisfechos al ser deuda pública.

En definitiva, la posible rehabilitación en Maratón de atimoi que habían permanecido en el Ática, junto con la liberación de esclavos, seguiría la misma dinámica que en el 405 y que en la crisis derivada de Queronea. En la rehabilitación de finales del siglo $\mathrm{V}$, además, se dio el agravante de que se había producido una reducción drástica de la población ciudadana por la guerra prolongada y especialmente después de Sicilia. En cálculos de Hansen, al final de la contienda habría menos de la mitad de lo que había al inicio del enfrentamiento. ${ }^{126}$ Esta situación de crisis demográfica es lo que había llevado probablemente a tomar medidas excepcionales también en política matrimonial en ese periodo. Durante la guerra se permitió teóricamente estar casado con una mujer y tener hijos con otra ${ }^{127}$ y se relajó o se abolió la ley de ciudadanía de Pericles. ${ }^{128}$ Posiblemente fueron validados muchos matrimonios o uniones entre mujeres atenienses (viudas) y metecos, nothoi y atimoi, así como los nacidos de convivencias ilegales o concubinatos, que quedaron finalmente integrados en la ciudadanía gracias a la enmienda de Nicomenes a la ley de Aristofonte que revalidaba la ley de ciudanía de Pericles en el 403 pero sin carácter retroactivo. ${ }^{129}$ Esta crisis demográfica en plena guerra se manifestó en la necesidad de reclutar no sólo a una gran cantidad de esclavos (y asegurarse su lealtad, en las Arginusas, por ejemplo) y a extranjeros en la flota, ${ }^{130}$ sino en la tendencia a ampliar el número de ciudadanos, como ya hemos señalado. ${ }^{131}$ El mismo Andócides en su discurso menciona la integración de extranjeros como remedio a la "escasez de ciudadanos".

De este modo, podemos concluir que la casuística y la extensión de los inscritos como atimoi por deuda públicos pudieron ser más amplias de lo que se imagina, afectando, sin duda, a grandes propietarios, pero también a gentes modestas con patrimonios

123 Ver nota 99

124 Así parece inferirse de Aristófanes (Lys. 665); ver Valdés (2003, p. 81 con n. 56 y 84-85), con bibliografía.

125 Arist. [Ath. Pol.] 16.2-5.

126 Ver nota 112

127 Ogden (1996, pp. 75-76); Kears (2013, pp. 159-160). Para legislación matrimonial y descendencia: Harrison (1968, pp. 1-96).

128 Algunos autores creen que la ley de Pericles fue derogada durante la Guerra del Peloponeso: Strauss (1986, p. 74); ver, sin embargo, Patterson (1981, pp. 145-147). Ver para la discusión sobre el tema: Ogden (1996, p. 73 y ss.); Blok (2009, pp. 143-144); Kears (2013, pp. 158-161).

129 Ley de Aristofonte del 403: Caryst. Fr. 11 (Ath. 13.577b-c). Sin carácter retroactivo gracias a una enmienda de Nicomenes (Eumelos FrGrHist 77 F2 en el sch. Aeschines 1.39).

130 Valdés (2020).

131 Plateos, samios, atimoi, esclavos y metecos con Trasibulo: ver notas 101-104. 132 And. 1.149 . 
medianos o pequeños. La motivación principal de su rehabilitación fue, sin duda, la situación de crisis y la emergencia militar y demográfica en distintos contextos (Maratón, Guerra del Peloponeso, Queronea), pero no pueden descartarse, tampoco, junto a ello, la existencia de determinadas corrientes, dentro del demos, que vieran con buenos ojos la ampliación de la ciudadanía a determinados sectores excluidos, como había ocurrido ya en momentos excepcionales, con Solón o con Clístenes. ${ }^{133}$ Otro tema, no necesariamente incompatible, es el de los exiliados por motivos políticos, elemento que se manifestó de forma mucho más fuerte en la amnistía del 404 y tras la restauración democrática del 403, a pesar de que ahí también estuvieron presentes, sin duda, las necesidades demográficas. Así y todo, en esos momentos "se cerró" la ciudadanía con la reedición de la ley Pericles y, aunque se reconocieron como ciudadanos-gracias a la enmienda de Nicomenes- ${ }^{134}$ a muchos irregularmente inscritos o que se habían hecho pasar como politai durante la guerra, se rechazó la naturalización de metecos y esclavos que habían luchado por la restauración ${ }^{135}$ e incluso se planteó, sin éxito, la expulsión de los "sin tierras". ${ }^{136} \mathrm{Y}$ es que parece que la democracia toma un sesgo más "moderado", pero eso ya es otra cuestión, no exenta tampoco de discusión.

133 Para Clístenes: Plácido (1985)



135 Ver nota 104.

136 Propuesta de Formisio: Lisias, 34 (Sobre la abolición en Atenas de la constitución de los antepasados), argumento, según Dionisio: Dion. Hal. Lys. 32-33.

137 Democracia moderada: Hansen (1991, 159-60, 288, 300-304). Contra la existencia de una línea moderada: Sancho (2004). Ver, sin embargo, Gallego (2012, 4 ss); Plácido (2017, 25 ss). 


\section{Dibliografía}

"Allen, D. S. (2000). The World of Prometheus. The politics of punishing in democratic Athens. Princeton: Princeton University Press.

" Blok, J. (2009). Pericles' Citizenship Law: A New Perspective. Historia, 58, 141-170.

» Blok, J. (2017). Citizenship in Classical Athens. Cambridge: Cambridge University Press.

» Boegehold, A. L. (1990). Andokides and the Decree of Patrokleides. Historia, 39(2), 149162.

»Canevaro, M. y Harris, E. M. (2012). The Documents in Andocides' on the Mysterires, CQ, 6(1), 98-129.

"Canevaro, M. y Harris, E. M. (2016-2017). The Authenticity of the Documents at Andocides' On the Mysteries 77-79 and 83-84. Dike, 19/20, 9-49.

"Carawan, E. (2002). The Athenian amnesty and the "scrutiny of the laws".JHS, 122, 1-23.

»Carawan, E. (2013). The Athenian Amnesty and Reconstructing the Law. Oxford: Oxford University Press.

" Carey, Ch. (2018). Bridging the Divide Between Public and Private: Dikē Exoulēs and Other Hybrids. En Ch. Carey et al. (Eds.), Use and Abuse of Law in the Athenian Courts (7691). Leiden/Boston: Brill.

"Carey, Ch. et al. (2008). Fragments of Hyperides' Against Diondas from the Archimedes Palimpsest. ZPE, 165, 1-19.

»Christ, M. R. (1998). Legal Self-Help on Private Property in Classical Athens. AJA, 119(4), 521-545.

»Coscolla, M. J. (2000). Ampliación y exclusión del cuerpo de la ciudadanía de Aristófanes. Anales De Historia Antigua, Medieval y Moderna, 33, 5-22.

"Dmitriev, S. (2015). Athenian Atimia and Legislation Against Tyranny and Subversion. CQ, 65(1), 35-50.

"Eggers Lan, C. (1988). Platón. Diálogos IV. República. Madrid: Gredos.

"Fantasia, U. y Carusi, C. (2004). Revisioni e controlli delle liste dei cittadini: La diapsephisis ateniese del 346/5 a.C. En S. Cataldi (Ed.), Poleis e politeiai: esperienze politiche, tradizioni letterarie, progetti costituzionali (187-216). Alexandria: Edizioni dell'Orso.

» Finley, M. I. (1980). Ancient Slavery and Modern Ideology. New York: The Viking Press.

» Gallego, J. (2012). La liberación del dêmos, la memoria silenciada. Atenas, de la violencia oligárquica a la amnistía. Anales de Historia Antigua, Medieval y Moderna, 44, 1-16.

" García Domingo, E. (2015). Algunas observaciones sobre la "atimía". Cuadernos de Filología Clásica. Estudios Griegos e Indoeuropeos, 25, 85-113.

" Halm-Tisserant, M. (2013). Réalités et imaginaires des supplices en Grèce ancienne. (1st ed. 1998). Paris: Les Belles Lettres.

" Hamel, D. (1998). Coming to Terms with Lipotaxion. GRBS, 39, 361-405.

"Hansen, M. H. (1976). Apagoge, Endeixis and Ephegesis against kakourgoi, Atimoi and Pheugontes. A Study in the Athenian Administration of Justice in the Fourth Century BC. Odense: Odense University Press. 
» Hansen, M. H. (1980). Seven Hundred Archai in Classical Athens. GRBS, 21, 151-173.

» Hansen, M. H. (1982). Atimia in Consequence of Private Debts. En J. Modrzejewski y D. Liebs (Eds.), Symposion 1977. Vortrage zur griechischen und hellenistischen Rechtsgeschichte (113-120). Köln: Böhlau.

» Hansen, M. H. (1991). The Athenian democracy in the age of Demosthenes. Structure, principles and ideo-logy. Oxford: Blackwell.

» Hansen, M. H. (2015). Is Patrokleides' Decree (Andoc. 1.77-79) a Genuine Document? GRBS, 55, 884-901.

» Harris, E. M. (2013). The Against Meidias (Dem. 21). En M. Canevaro (Ed.), The documents in the attic orators: laws and decrees in the public speeches of the Demosthenic corpus (209236). Oxford: Oxford University Press.

» Harrison, A. R. W. (1968). The Law of Athens. The Family and Property. Vol. I. Oxford: Oxford University Press.

" Harrison, A. R. W. (1971). The Law of Athens. Procedure. Vol. II. Oxford: Oxford University Press.

"Holmes, B. (2010). Marked Bodies. Gender, Race, Class, Age, Disability and Disease. En D. H. Garrison (Ed.), A Cultural History of the Human Body in Antiquity (159-183). Oxford and New York: Berg.

»Hunt, P. (2001). The Slaves and the Generals of Arginusae. AJA, 122, 359-380.

» Hunter, V. (1992). Constructing the Body of the Citizen. EMC, 36, 271-91.

»Hunter, V. (2000). Policing Public Debtors in Classical Athens. Phoenix, 54, 21-38.

»Internationale des Droits de l'Antiquité (third series), 42, 71-113.

» Joyce, Ch. (2018). Atimia and Outlawry in Archaic and Classical Greece. Polis. The Journal for Ancient Greek and Roman Political Thought, 35(1), 33-60.

» Kamen, D. (2009). Servile Invective in Classical Athens. Scripta classica israelica, 28, 4356.

» Kamen, D. (2013). Status in Classical Athens, Princeton and Oxford: Princeton University Press.

» Kapparis, K. (2005). Immigration and Citizenship Procedures in Athenian Law. Revue

» Kears, M. J. (2013). Metics and Identity in Democratic Athens. Ph.D. University of Birmingham, Reino Unido.

» Konstan, D. (1995). Greek Comedy and Ideology. Oxford: Oxford University Press.

» Lape, S. (2010). Race and Citizen Identity in the Classical Athenian Democracy, Cambridge: Cambridge University Press.

» Loddo, L. (2019). Voluntary Exile and Eisangelia in Athens: Remarks about the Lawfulness of a Widespread Practice. Dike, 22, 113-16o.

»Loraux, N. (2008 [2005]). La guerra civil en Atenas. La política en la sombra y la utopía (Trad. Iriarte, A.). Madrid: Akal.

» Macía Aparicio, L. (2007a). Aristófanes. Comedias II, Introducciones, traducción y notas de Nubes; Avispas; Paz; Pájaros. Madrid: Gredos.

» Macía Aparicio, L. (2007b). Aristófanes. Comedias III, Introducciones, traducción y notas de Lisístrata, Las Tesmoforías; Las ranas; La Asamblea de las mujeres. Madrid: Gredos.

» MacDowell, D. M. (1962). Andokides, On the Mysteries. Oxford: Clarendon Press. 
» MacDowell, D. M. (1978). The Law in Classical Athens. London: Thames and Hudson.

» Mactoux, M.-M. (1980). Douleia. Esclavage et pratiques discursives dans l'Athènes classique. Paris: Les Belles Lettres.

» Maffi, A. (1983). ATIMAZEIN E ФEYГEIN nei poemi omerici. En P. Dimakis (Ed.), Symposion 1979. Vorträge zur griechischen und hellenistischen Rechtsgeschichte (251-261). Köln/ Wien: Böhlau.

» Maffi, A. (2018). Outlawry and Atimia: Response to Maria Youni. En G. Thür, U. Yiftach y R. Zelnick-Abramowitz (Eds.), Symposion 2017. Vorträge zur griechischen und hellenistischen Rechtsgeschichte (Tel Aviv, 20.-23. August 2017) (157-164). Wien: Verlag der österreichischen Akademie der Wissenschaften.

» Manville, B. (1980). Solon's Law of Stasis and Atimia in Archaic Athens. TAPhA, 110, 213221.

» Muñoz Flórez, J. (2011). El nuevo Hiperides In Diondam: introducción, traducción y notas. Cuadernos de Filología Clásica. Estudios griegos e indoeuropeos, 21, 193-230.

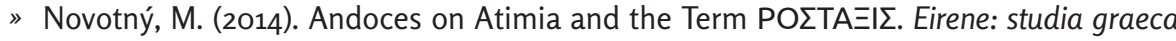
et Latina, 50, 61-88.

» Ogden, D. (1996). Greek Bastardy in the Classical and Hellenistic Periods. Oxford/New York: Oxford University Press.

»Osborne, R. (1985). Law in Action in Classical Athens. JHS, 105, 40-58.

» Osborne, R. (1988). Social and Economic Implications of the Leasing of Land and Property in Classical and Hellenistic Greece. Chiron, 18, 279-323.

»Pallí Bonet, J. (1985). Aristóteles. Ética Nicomáquea. Ética Eudemia. Madrid: Gredos.

»Paiaro, D. (2008). Terratenientes, campesinos y arriendo de tierras en la Atenas del siglo V a. C. Circe, 12, 207-223.

» Paiaro, D. (2020). “...tierras de labranza por rentas moderadas [georgías epì metríais misthósesi] (Isoc. 7.32). Explotación y relaciones de trabajo rural entre los ciudadanos atenienses durante la democracia. Sociedades Precapitalistas, 10.

» Patterson, C. (1981). Pericles' Citizenship Law of 451-50 B.C. New York: Arno Press.

»Pébarthe, Ch. (2006). Cité, démocratie et écriture: histoire de l'alphabétisation d'Athènes à l'époque Classique. Paris: De Boccard.

» Piérart, M. (1971). Les عüӨuvo athéniens. AntCl, 40, 526-673.

» Plácido, D. (1985). Esclavos metecos. En N. Marín Díaz (Ed.), Homenaje in memoriam Agustín Díaz Toledo (297-303). Granada/Almería: Universidad de Granada.

» Plácido, D. (2006). Liturgias, evergetismo y mistoforía: los modos de redistribución de la ciudad democrática. En F. Marco, F. Pina y J. Remesal (Eds.), Repúblicas y ciudadanos: modelos de participación cívica en el mundo antiguo (41-54). Barcelona: Universidad de Barcelona.

»Plácido, D. (2008). Las relaciones clientelares en la evolución de la democracia ateniense. Circe, 12, 225-242.

» Plácido, D. (2012). Las formas de dependencia en Atenas en la transición hacia el Helenismo. En A. Pinzone, E. Camiri y R. Arcuri (Eds.), Forme di dipendenza nelle società di transizione. Atti del XXXII Colloquio Internazionale GIREA, (Mesina 15-17 maggio 2008) (57-64). Mesina: Di.SC.A.M.

» Plácido, D. (2017). La crisis de la ciudad clásica y el nacimiento del mundo helenístico, Buenos Aires: Miño y Dávila. 
»Plácido, D. y Fornis, C. (2011). Evergetismo y relaciones clientelares en la sociedad ateniense del s. IV a. C. DHA, 37(2), 19-47.

»Poddighe, E. (2006). Ateniesi infami (atimoi) ed ex Ateniesi senza i requisiti (apepsephismenoi). Nuove osservazioni in margine al fr. 29 Jensen di Iperide sulle diverse forme di esclusione dal corpo civico di Atene. Annali della Facotà di Lettere e Filosofía, 61, 5-24.

» Redondo Sánchez, J. (1991). Antifonte. Andócides. Discursos y fragmentos. Madrid: Gredos.

» Rhodes, P. J. (1972). The Athenian Boule. Oxford: Clarendon Press.

» Rhodes, P. J. (1981). A Commentary on the Aristotelian Athenaion Politeia. Oxford: Oxford University Press.

» Rihll, T. E. (1991). Hektemoroi: Partners in Crime? JHS, 111, 122-123.

» Rubinstein, L. (2000). Litigation and Cooperation: Supporting Speakers in the Courts of Classical Athens. Stuttgart: Franz Steiner Verlag.

» Rubinstein, L. (2018). The Athenian Amnesty of 403/2 and the Forgotten 'Amnesty' of 405/4. En W. Riess (Ed.), Colloquia Attica. Neuere Forschungen zur Archaik, zur athenischen Recht und zur Magie (123-144). Stuttgart: Franz Steiner Verlag.

»Sancho, L. (2004). Los “moderados" atenienses y la implantación de la oligarquía. Corrientes políticas en Atenas entre 411 y 403 a. C. Veleia, 21, 73-98.

»Scafuro, A. (2014). Patterns of Penalty in Fifth Century Attic Decrees. En A. P. Matthaiou y R. K. Pitt (Eds.), Athenaion episkopos: Studies in Honour of Harold B. Mattingly (299326). Athēnai: Hellēnikē Epigraphikē Hetaireia.

»Shear, J. L. (2011). Polis and Revolution: Responding to Oligarchy in Classical Athens. Cambridge/New York: Cambridge University Press.

» Sickinger, J. P. (1999). Public Records and Archives in Classical Athens. Chapel Hill: University of North Carolina Press.

» Sommerstein, A. H. (1990). The Comedies of Aristophanes. Vol. 7: Lysistrata. Warminster: Aris \& Phillips.

»Strauss, B. S. (1986). Athens after the Peloponnesian War. Class, Faction and Policy 403-386 $B C$. London/Sydney: Croom Helm.

»Swoboda, I. H. (1893). Arthmios von Zeleia. Archaeologische-epigrafische Mittheilungen, $16,46-98$.

» Teegarden, D. A. (2014). Death to Tyrants! Ancient Greek Democracy and the Struggle against Tyranny. Princeton: Princeton University Press.

» Thür, G. (2015). Transactions Costs in Athenian Law. En D. P. Kehoe, D. Ratzan y U. Yiftach (Eds.), Law and Transaction Costs in the Ancient Economy (36-50). Ann Arbor: University of Michigan Press.

»Valdés Guía, M. (2003). Entre el consejo de Solón y el de Clístenes: ¿Heliea en época de Pisístrato? Gerión, 21, 73-91.

»Valdés Guía, M. (2007). Peur et contrainte des dépendants ratifiés par pratiques judiciaires et religieuses: les paysans atimoi de l'Attique archaïque. En A. Serghidou (Ed.), Peur de l'esclave, peur de l'esclavage en Méditerranée ancienne (Discours, représentations, pratiques), Actes du XXIXe colloque du Groupe International de Recherche sur l'Esclavage dans l'Antiquité (GIREA)- Rhetymnon 4-7 Novembre 2004 (99-114). Besançon: PUFC.

»Valdés Guía, M. (2015). La renovación de la dependencia en el s. IV: los espacios de thetes y misthotoi. En A. Beltrán, I. Sastre y M. Valdés (Eds.), Los espacios de la esclavitud y de la dependencia desde la Antigüedad. Homenaje a Domingo Plácido. Actas del XXXV 
Congreso del GIREA (Madrid, 28 al 30 de nov. de 2012) (183-199). Besançon: PUFC.

»Valdés Guía, M. (2018). De los ptochoi homéricos a los del s. IV: lo viejo y lo nuevo, mendicidad y evergesía. En J. Cortadella, O. Olesti y C. Sierra (Eds.), Lo viejo y lo nuevo en las sociedades antiguas (XXXVI Coloquio del GIREA) (103-119). Besançon: PUFC.

»Valdés Guía, M. (2019a). Hybris en Atenas arcaica: explotación y formas de violencia de los aristoi frente al demos. En A. Gonzales (Ed.), Praxis e Ideologías de la Violencia. Para una anatomía de las sociedades patriarcales esclavistas desde la Antigüedad. Homenaje a Amparo Pedregal (169-196). Besançon: PUFC.

»Valdés Guía, M. (2019b). Los excluidos de la ciudadanía con la ley de Pericles (Plut. Per. 37.3-4): algunas reflexiones sobre ciudadanos, extranjeros y esclavos en Atenas del s. V a. C. De Rebus Antiquis, 9, 19-41.

»Valdés Guía, M. (2020). Los thetes y la flota ateniense en el s. V: ¿una cuestión retórica? En M. Pi Corrales et al. (Eds,), La Batalla: análisis históricos y militares (IV Congreso Internacional de la Cátedra Extraordinaria Complutense de Historia Militar) (163-208). Madrid: Cátedra Extraordinaria Complutense de Historia Militar (impresión: Or5o S.L.).

» Van Wees, H. (2018). Citizens and Soldiers in Archaic Athens. En A. Duplouy y R. W. Brock (Eds.), Defining Citizenship in Archaic Greece (1-46). Oxford: Oxford University Press.

»Vetter, L. P. (2005). Women's Work as Political Art: Weaving and Dialectical Politics in Homer, Aristophanes, and Plato. Lanham: University Press of America.

»Wallace, R. W. (1998). Unconvicted or Potential Atimoi in Ancient Athens. Dike, 1, 63-78.

» Youni, M. S. (2001). The Different Categories of Unpunished Killing and the term

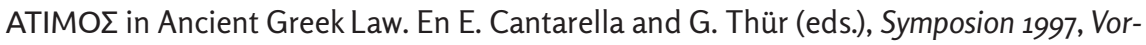
träge zur griechischen und hellenistischen Rechtsgeschichte (117-134). Köln/Wien: Böhlau.

» Youni, M. S. (2018). Outlawry in Classical Athens: Nothing to Do with Atimia. En G. Thür, U. Yiftach y R. Zelnick-Abramowitz (Eds.), Symposion 2017. Vorträge zur griechischen und hellenistischen Rechtsgeschichte (Tel Aviv, 20.-23. August 2017) (137-155). Wien: Verlag der österreichischen Akademie der Wissenschaften. 